\title{
MODELOS PARA DADOS CATEGORIZADOS ORDINAIS: APLICAÇÕES EM AGROPECUÁRIA
}

\section{MARIA HELENA SPYRIDES-CUNHA}

Bacharel em Estatística

Orientadora: Prof. $^{a}$ Dr. $^{a}$ CLARICE G. B. DEMÉTRIO

Dissertação apresentada à Escola Superior de Agricultura "Luiz de Queiroz", Universidade de São Paulo, para obtenção do título de Mestre em Agronomia, Área de Concentração: Estatística e Experimentação Agronômica.

PIRACICABA

Estado de São Paulo - Brasil

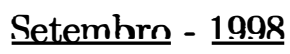


Dados Internacionais de Catalogação na Publicação (CIP) DIVISĀO DE BIBLIOTECA E DOCUMENTAÇĀO - Campus "Luiz de Queiroz"/USP

Spyrides-Cunha, Maria Helena

Modelos para dados categorizados ordinais: aplicaçōes em agropecuária / Maria Helena Spyrides-Cunha. - - Piracicaba, 1998.

80 p. : il.

Dissertação (mestrado) - - Escola Superior de Agricultura Luiz de Queiroz, 1998. Bibliografia.

1. Análise de estatistica 2. Método de maxima verossimilhança I. Titulo

CDD 519.53 
Aos meus pais

Constantino (in memorian) e Kyrana,

\section{agradeço.}

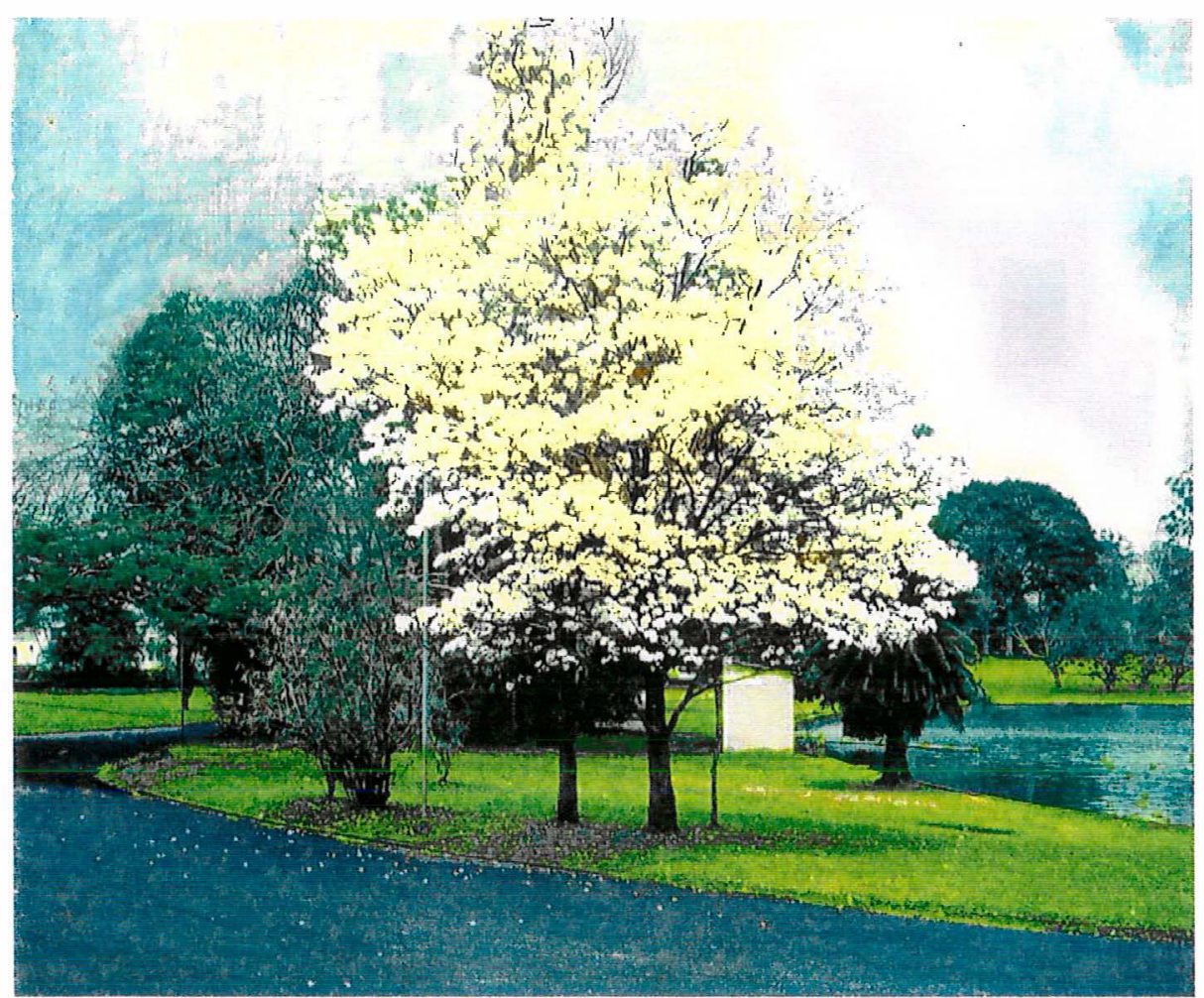

ESALQ/USP-Piracicaba/SP

Ao Totonho e aos meus filhos

Marcelo e Ana Paula

pelo apoio e compreensão, 


\title{
AGRADECIMENTOS
}

\author{
A Deus \\ por me guiar num caminho de luz, energia $e$ \\ amor, acompanhando-me passo a passo nesta \\ escola da vida.
}

Expresso aqui meus agradecimentos a todos aqueles que de algum modo colaboraram para a realização deste trabalho.

A Prof. ${ }^{a} \operatorname{Dr}^{a}$ Clarice G. B. Demétrio, pela orientação e confiança no desenvolvimento deste trabalho contribuindo no meu amadurecimento profissional;

Aos professores e funcionários da Universidade Federal do Rio Grande do NorteUFRN, pela oportunidade e incentivo;

À CAPES/UFRN, pela bolsa de estudos;

Ao amigo Cristián Andrés Carranza, pela elaboração dos gráficos e, principalmente, pelo estímulo e companheirismo nesta trajetória, contribuindo de forma significativa para a realização deste trabalho;

A amiga Jeanete Alves Moreira, pela força e apoio nos momentos difíceis amenizados por suas palavras de incentivo e carinho;

À grande família de amigos da Pós-graduação, com quem convivī e tornaram este período cheio de muita amizade, carinho, confiança e motivação, em especial ao Afrânio, Idemauro, Adilson, Wilson, Sandra, Sívia e Liciana;

Aos professores do Departamento de Matemática e Estatística da Escola Superior de Agricultura Luiz de Queiroz, pela transmissão dos conhecimentos; 
Ao Prof. Dr. Luis E. A. Camargo, do Departamento de Fitopatologia da Escola Superior de Agricultura Luiz de Queiroz, pela forma harmoniosa e dinâmica em nosso trabalho conjunto;

Ao PhD Rory Wolfe, do Royal Children's Hospital, Austrália, pelos esclarecimentos de forma clara e detalhada nos momentos de dúvidas e pela grande atenção dedicada;

A EMBRAPA Suínos e Aves de Concórdia (SC), pela concessão no uso dos dados, em especial aos pesquisadores Waldomiro Barioni e Nelson Mores;

Aos funcionários do Departamento de Matemática e Estatística da Escola Superior de Agricultura Luiz de Queiroz, pela atenção e dedicação;

Ao Dr. Joãodenir Furlan e Suely P. N. Silva, do setor de assistência social da ESALQ, pelo apoio emocional oferecido com muita dedicação;

Aos meus irmãos e amigos de Natal que me apoiaram e incentivaram a ir em busca de mais uma conquista em minha vida;

Aos meus pais, pela educação nesta escola maior;

Ao Totonho, por suprir a minha ausência junto aos filhos e por ter me apoiado nesta decisão;

Aos filhos Marcelo e Ana Paula, por serem a mola mestre que me propulsiona a ir além, dando-me estímulo e todos os elementos necessários para enfrentar esta grande engrenagem... 


\section{SUMÁRIO}

Página

LISTA DE FIGURAS $\ldots \ldots \ldots \ldots \ldots \ldots \ldots \ldots$. . . . . . . . . .

LISTA DE TABELAS $\ldots \ldots \ldots \ldots \ldots \ldots \ldots$. . . . . . . . . . . . .

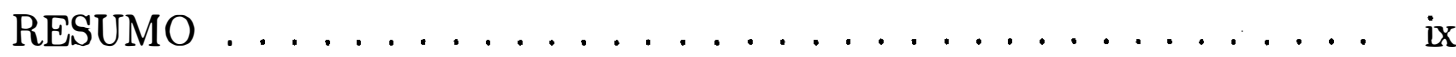

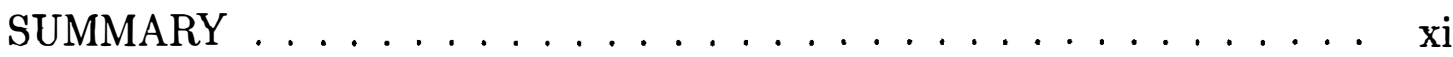

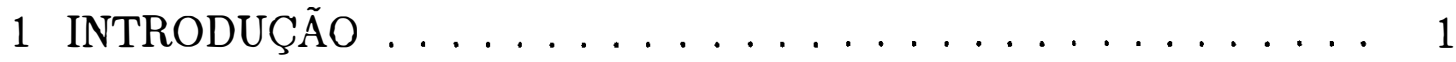

2 REVISÃO DE LITERATURA . . . . . . . . . . . . . . . 4

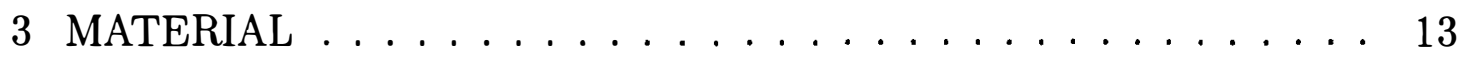

3.1 Aplicação em Fitopatologia $\ldots \ldots \ldots \ldots$

3.2 Aplicação em Zootecnia . . . . . . . . . . . . . . . . . . . . . 16

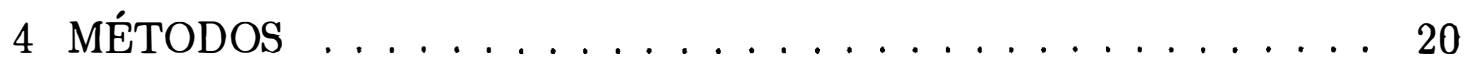

4.1 Dados Categorizados . . . . . . . . . . . . . . . . . . . 20

4.2 Tabelas de Contingência . . . . . . . . . . . . . . . . 21

4.2 .1 Notação e Definições . . . . . . . . . . . . . . . . . . . . . . 21

4.2 .2 Esquemas de Amostragem . . . . . . . . . . . . . . . . . . . . . 24

4.2.3 Razão de Chances - ("Odds Ratio") . . . . . . . . . . . . . . . . . 26

4.3 Modelos Lineares Generalizados . . . . . . . . . . . . . . . . . . . 32

4.4 Adequacidade dos Modelos . . . . . . . . . . . . . . . . . 34

4.4 .1 Introdução. . . . . . . . . . . . . . . . . . . . . . 34

4.4.2 Estatísticas de Pearson e Razão de Verossimilhança . . . . . . . . . 34

4.4 .3 Resíduos . . . . . . . . . . . . . . . . . . . . . 36

4.5 Modelos para Dados Categorizados Ordinais . . . . . . . . . . 37

4.5.1 Modelos Log-lineares . . . . . . . . . . . . . . . . . . . . 37

4.5.1.1 Modelo de Associação Uniforme (Linear $\times$ Linear) $\ldots \ldots$. . . 38

4.5.1.2 Modelo de Efeito de Linhas e Colunas . . . . . . . . . . . . . . 41

4.5 .2 Modelos "Logit" . . . . . . . . . . . . . . . . . . . . . 43 
4.5.2.1 Modelo de Chances Proporcionais . . . . . . . . . . . . . . . . 45

4.5.2.2 Modelo de Riscos Proporcionais . . . . . . . . . . . . . . . 50

4.5.2.3 Modelos com Efeito de Escala . . . . . . . . . . . . . . . . . 51

4.5.2.4 Outros tipos de modelos "Logit" . . . . . . . . . . . . . . . 52

4.5 .3 Exemplos de Aplicação . . . . . . . . . . . . . . . . . . . . 53

4.5.3.1 Aplicação em Fitopatologia . . . . . . . . . . . . . . . . . 53

4.5.3.2 Aplicação em Zootecnia . . . . . . . . . . . . . . . . . . . . . 54

5 RESULTADOS E DISCUSSÃO . . . . . . . . . . . . . . . 56

5.1 Aplicação em Fitopatologia . . . . . . . . . . . . . . 56

5.2 Aplicação em Zootecnia . . . . . . . . . . . . . . . . . . . . . 62

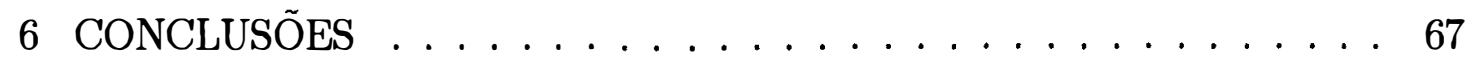

REFERÊNCIAS BIBLIOGRÁFICAS . . . . . . . . . . . . . . 69

APENDICE $1 \ldots \ldots \ldots \ldots \ldots \ldots \ldots$

APÊNDICE $2 \ldots \ldots \ldots \ldots \ldots \ldots \ldots$ 


\section{LISTA DE FIGURAS}

Página

1 Grau de severidade da doença - Escala padrão. . . . . . . . . . . 15

2 Razão de Chances Local. . . . . . . . . . . . . . . . . . . . . . . . . . 29

3 Razão de Chances Local-Global. . . . . . . . . . . . . . . . . . . . . . 30

4 Distribuição 1 estocasticamente maior que a distribuição 2: (a) estocasticamente ordenada; (b) não estocasticamente ordenada. . . . . . . 31

5 Razão de Chances Global. . . . . . . . . . . . . . . . . . . . . . . . . 32

6 Probabilidades de resposta para o modelo de chances proporcionais variando com $x$ quando $\beta>0 \ldots \ldots \ldots \ldots \ldots \ldots$

7 Probabilidades de resposta para o modelo complemento log-log variando com $x$ quando $\beta>0 \ldots \ldots \ldots \ldots \ldots$

8 Probabilidade acumulada até a j-ésima categoria de nota atribuída à Ferrugem Comum provocada por Puccinia sorghi em milho. . . . . . . 58

9 Dispersão dos Resíduos. . . . . . . . . . . . . . . . . . . . . . . 59 


\section{LISTA DE TABELAS}

Página

1 Descrição das variáveis explicativas categorizadas nominais. . . . . 17

2 Descrição das variáveis explicativas categorizadas ordinais. . . . . . 18

3 Descrição das variáveis suplementares (contínuas) . . . . . . . . . . . 19

4 Notação para as frequências observadas e totais marginais. . . . . . . 22

5 Notação para as proporções observadas. . . . . . . . . . . . . . . . . 22

6 Notação para as probabilidades conjunta, condicional e marginal. . . 23

$7 \quad$ Tipos de modelos para análise estatística. . . . . . . . . . . . . . . . 33

8 Termos de associação para modelos log-lineares em tabelas de contingência tridimensional com efeitos ordinais lineares. . . . . . . . . . 43

9 Graus de liberdade para modelos log-lineares em tabelas de contingência tridimensional com efeitos ordinais lineares. . . . . . . . . 43

10 Probabilidades acumuladas das categorias ordinais. . . . . . . . . 45

11 Termos de associação e graus de liberdade para modelos de chances proporcionais, com resposta ordinal $\mathrm{Z}$ e efeitos lineares de variáveis explicativas ordinais. . . . . . . . . . . . . . . 50

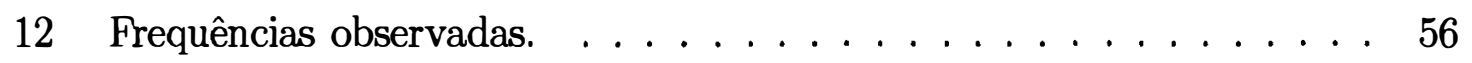

13 Probabilidades acumuladas observadas até a j-ésima categoria. . . . . 57

14 Análise de Deviance. . . . . . . . . . . . . . . . . . . . . . . 58

15 Estimativas de Máxima Verossimilhança. . . . . . . . . . . . . . 61

16 Intervalos de confiança de $95 \%$ para as razões de chances. . . . . . . . 61

17 Deviance residual para o ajuste dos modelos de chances proporcionais e riscos proporcionais e diferenças de deviances para a significância do parâmetro. . . . . . . . . . . . . . . . . . . . 62 
18 Deviance residual para o ajuste dos modelos de chances proporcionais e riscos proporcionais e diferenças de deviances para a significância do parâmetro. . . . . . . . . . . . . . . . . . . . 63

19 Deviance residual para o ajuste dos modelos de chances proporcionais e riscos proporcionais e diferenças de deviances para a significância do parâmetro. . . . . . . . . . . . . . . . . . . . . . . 64

20 Significância dos parâmetros, modelo de riscos proporcionais. . . . . . 65

21 Estudo das interações dos fatores de risco ajustados ao modelo de

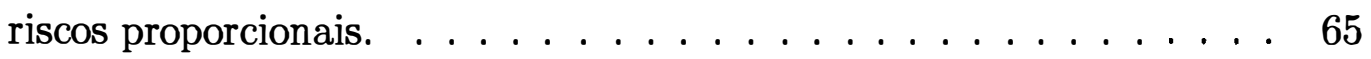

22 Estimativas dos parâmetros do modelo de riscos proporcionais. . . . . 66 


\title{
MODELOS PARA DADOS CATEGORIZADOS ORDINAIS: APLICAÇŌES EM AGROPECUÁRIA
}

\author{
Autora: MARIA HELENA SPYRIDES-CUNHA \\ Orientadora: Prof. ${ }^{a}$ Dr. $^{a}$ CLARICE G. B. DEMÉTRIO
}

\section{RESUMO}

Geralmente, em estudos para avaliar o grau de severidade de doenças em plantas e animais, é comum a atribuição de escores numa escala ordinal como medida de mensuração. Este tipo de variável resposta, porém, não segue uma distribuição normal e os profissionais na maioria das vezes são levados a usar recursos para assegurar as pressuposições exigidas pela análise de variância. Estes dados, no entanto, podem ser modelados através de técnicas específicas para dados categorizados ordinais.

Este trabalho apresenta duas aplicações, uma em agronomia e outra em zootecnia, ilustrando respectivamente os modelos de chances proporcionais e riscos proporcionais. No primeiro exemplo, o interesse consistiu em avaliar o grau de associação entre dois marcadores moleculares, um localizado no cromossomo 2 (bngl669) e outro no cromossomo 8 (bngl166), e o grau de severidade da ferrugem comum em milho, causada pelo agente Puccinia sorghi. Verificou-se tanto o efeito individual destes marcadores moleculares quanto a presença de epistase sobre o grau de severidade da doença. Concluiu-se que a combinação genotípica de maior resistência à Puccinia sorghi foi 11 para o bngl669 e 22 para o bngl166. No segundo exemplo, o objetivo foi o de identificar os fatores de risco associados à diarréia em leitões em período de desmama, a fim de caracterizar o máximo de informação do ecossistema 
nas maternidades. Constatou-se que a vacinação contra a colibacilose, o tratamento com oxitocina, o aleitamento em grupo e a patologia de parto das porcas favorecem a diarréia nas granjas. 


\title{
ORDINAL CATEGORICAL DATA MODELS: AGRONOMY AND ANIMAL SCIENCE APLICATIONS
}

\author{
Author: MARIA HELENA SPYRIDES-CUNHA \\ Adviser: Prof. ${ }^{a}$ Dr. ${ }^{a}$ CLARICE G. B. DEMÉTRIO
}

\section{SUMMARY}

In research of disease resistance involving plants and animals, it is very common the attribution of scores in an ordinal scale. Most statistical approaches, however, require a continuous distribution of the response variable, a requirement not always met. Nevertheless, this kind of data can be powerfully analysed through ordinal categorical response techniques.

This work presents two applications, one in agronomy and another in animal science. The first example is an application of the proportional odds model in detecting the association between genotypes of two molecular-marker loci and the severity disease of "common rust" in maize, caused by Puccinia sorghi. Singlemarker analyses detected significant differences among marker genotypes at both marker loci, indicating that these marker are linked to disease resistance. Moreover, the inclusion of the interaction term after the single-marker analyses indicated a strong evidence of epistatic interaction between the bngl166 (chromossome 2) and bngl699 (chromossome 8). The aim of the second example was to identify some of the risk factors associated with the diarrhea in nursing piglets, to describe the maximum of information about the environment system of the maternity. The analysis is an application of the proportional hazard model and showed that some of the factors in the farm stimulate the diarrhea, like: colibacillosis vacination, oxytocin treatment, group milking and farrowing pathology. 


\section{INTRODUÇÃO}

A busca pela melhoria na qualidade de produção dentro da área de Ciências Agropecuárias tem levado os profissionais ao estudo das causas que afetam algumas características de qualidade, a fim de serem evitadas perdas econômicas na produção. Em Zootecnia, estas causas podem estar relacionadas com higiene e saúde dos rebanhos, na Agronomia, podem estar ligadas a características genotípicas das plantas. As situações práticas com que um pesquisador se depara variam muito com a área de pesquisa e, em certos casos, não é possível medir a variável resposta através de uma escala contínua, como as variáveis peso, diâmetro, por exemplo. Isto, geralmente, ocorre quando as medidas são de difícil mensuração, como por exemplo, a atribuição de notas para avaliar o grau de severidade de determinada doença. Dados desse tipo enquadram-se no que é chamado resposta categorizada ordinal (Agresti, 1984).

Nas análises estatísticas destes dados, os profissionais acabam por usar técnicas mais comumente utilizadas como a análise de variância, forçando transformações nos dados para que os mesmos atendam aos pressupostos de homocedasticidade, linearidade e aditividade do modelo e normalidade dos resíduos, nem sempre conseguidos.

Neste tipo de pesquisa, porém, as observações consistem de contagens ou frequências dispostas em tabelas de contingência multidimensionais formadas através da classificação cruzada da variável resposta (colunas) e das variáveis ex-

plicativas (linhas), envolvendo distribuições do tipo Poisson, multinomial e produto multinomial, dentre outras.

A metodologia adequada para analisar dados de contagens é o modelo 
de regressão Poisson que é um caso particular dos Modelos Lineares Generalizados (MLG), desenvolvidos por Nelder \& Wedderburn (1972). McCullagh \& Nelder (1989) mostraram que distribuições multinomiais e produto multinomiais podem ser obtidas a partir de conjuntos de variáveis aleatórias com distribuição Poisson, condicionadas aos totais marginais fixados.

Casos particulares ocorrem quando as categorias assumidas pela resposta são ordenadas. McCullagh (1980), usando a natureza ordinal dos dados, propôs os modelos de chances proporcionais ("proportional odds") e de riscos proporcionais ("hazard models") para analisar dados desse tipo. Estes modelos são baseados em probabilidades acumuladas e são extensões multivariadas dos MLG.

O uso dos modelos que levam em consideração a natureza ordinal da variável resposta apresenta vantagens sobre a utilização de técnicas usuais de análise de dados categorizados (Agresti, 1984). Este método apresenta maior poder de teste para independência, usa modelos mais parcimoniosos e, não só detecta a associação, como também, descrevem certas tendências através de parâmetros de fácil interpretação, como as razões de chances.

As estimativas de máxima verossimilhança dos parâmetros são facilmente obtidas através de programas computacionais como o GLIM4 e o SAS, dentre outros, que utilizam o método dos mínimos quadrados reponderados iterativamente (IRLS).

O enfoque deste trabalho será dado aos modelos adequados à análise de dados categorizados ordinais, comuns em muitas aplicações nas Ciências Sociais, Biomédicas, Ecologia, Controle de Qualidade, Saúde Pública e as Engenharias, dentre outras, apresentando as vantagens dos modelos e a interpretação dos parâmetros que são utilizados para medir o grau de associação entre uma variável resposta ordinal e as variáveis explicativas nominais e/ou quantitativas em função da razão de chances.

Como aplicação são apresentados dois exemplos, um em Agronomia e outro em Zootecnia envolvendo, respectivamente, o Modelo de Chances Propor- 
cionais e o de Riscos Proporcionais, descritos por McCullagh (1980) na modelagem de uma única variável resposta medida em escala ordinal.

O primeiro exemplo refere-se ao cultivo de milho, de grande importância econômica e nutritiva no país. Devido às mais diversas adaptações em diferentes condições ecológicas, é a espécie botânica de maior diversidade genética existente na natureza, com cerca de mais de 300 variedades.

É, portanto, de fündamental importância para o desenvolvimento da cultura do milho, estudos que visem obter o máximo de informações que viabilizem uma melhor utilização de seu potencial genético. O ponto chave na melhoria genética do milho é identificar os genes que controlam a resistência, a produtividade e a qualidade. Genes que controlam estas características podem ser identificados através do uso da técnica de mapeamento por meio de marcadores moleculares. A estratégia geral envolve a genotipagem dos indivíduos de uma população segregante com marcadores moleculares distribuídos no genoma e avaliação de suas progênies para a característica em estudo, ou seja, uma característica quantitativa dos loci (QTL) (Liu, 1998).

Uma das doenças que afeta o milho é a "ferrugem comum", patologia causada por Puccinia sorghi. Os sintomas variam de acordo com a temperatura e regime de luz e manifestam-se através do aparecimento de pústulas sobre toda a área da planta, mas são especialmente numerosas sobre as folhas. À medida que aumenta a severidade da doença, as pústulas tornam-se mais numerosas e resultam na morte das folhas. Para avaliar o grau de resistência da planta é atribuída uma nota de acordo com a área afetada, numa escala de 1 a 9 , da mais resistente a mais suscetível, enquadrando-se no tipo de resposta categorizada ordinal.

Na suinocultura intensiva brasileira, as doenças são consideradas como as grandes responsáveis pela baixa performance e perda de animais. Uma delas é a prevalência de diarréia em leitões. No segundo exemplo, portanto, o interesse consiste em identificar os fatores de risco associados à diarréia em leitões com o intuito de caracterizar o máximo de informação possível do ecossistema nas maternidades. 


\section{REVISÃO DE LITERATURA}

O interesse de pesquisadores em resumir a associação entre variáveis com o uso de tabelas de classificação cruzada tem sua origem antes do século XX, porém, Pearson e Yule formularam os primeiros grandes estudos na análise de dados categorizados.

No início do século, Karl Pearson propôs o teste qui-quadrado para tabelas $2 \times 2$, logo ampliando o enfoque para duas ou mais variáveis através de uma partição de um conjunto multivariado de dados. A motivação de Pearson em desenvolver o teste qui-quadrado foi seu interesse em estudar se os resultados do jogo de roleta em Monte Carlo variavam aleatoriamente. Introduziu o termo "contingência" como uma medida do distanciamento da suposição de independência. Neste mesmo período, Yule, considerado por alguns autores como o fundador da escola de modelos log-lineares da análise de tabelas de contingência, observou que muitas variáveis categorizadas são discretas contrapondo-se às idéias de Pearson que sustentava a teoria de uma distribuição contínua subjacente. Criou medidas usando as contagens das caselas como a razão de chances. Os modelos para dados ordinais foram um tipo de reconciliação entre Yule e Pearson, já que as razões de chances caracterizam modelos que se ajustam bem quando as distribuições subjacentes são aproximadamente normais.

Fisher $^{1}$ (citado por Agresti, 1984) introduziu o conceito geométrico de graus de liberdade, demonstrando que o teste $\chi^{2}$ de Pearson possui $(r-1)(c-1)$ graus de liberdade e não o número de caselas menos 1 como afirmou Pearson.

\footnotetext{
${ }^{1}$ FISHER, R.A. On the interpretation of chi-square from contingency tables, and the calculation of P. Journal of Royal Statistical Society, No. 85, p. 87-94, 1922.
} 
Nos últimos quarenta anos com o avanço da informática em termos de maior velocidade dos equipamentos e pacotes computacionais específicos, tornou-se possível o desenvolvimento de novas técnicas de análise de dados categorizados e, por conseguinte, o surgimento de uma vasta literatura com artigos de Grizzle et al. (1969), Bishop (1975) e Goodman (1983), dentre outros expressivos, embora grupos diferentes de autores utilizem métodos diferentes de estimação.

Mais recentemente, Nelder \& Wedderburn (1972) ao desenvolverem os Modelos Lineares Generalizados (MLG), sugeriram o uso do método iterativo de Newton-Raphson para obter uma solução de máxima verossimilhança para o ajuste do modelo. Estes autores discutiram a utilidade dos MLG nos cursos de Estatística pois fornecem um modo consistente de ligar o componente sistemático em um modelo com o componente aleatório.

Uma das várias aplicações dos modelos lineares generalizados é em tabelas de contingência, porém, até então, não se tinha levado em consideração a natureza ordinal das variáveis em estudo. Haberman (1974) propôs os modelos log-lineares para tabelas de frequências com classificação ordenada, mostrando procedimentos para a seleção dos modelos, determinação das equações de máxima verossimilhança (MV), cálculo das estimativas de MV e determinação de variâncias assintóticas e testes. McCullagh (1980) descreveu vários modelos de ordenação estocástica como o Modelo de Chances Proporcionais ("Proportional Odds Models") e Modelo de Riscos Proporcionais ("Proportional Hazard Models") que são úteis na prática devido à simplicidade de interpretação.

Agresti $(1984,1990,1996)$ apresentou os modelos de análise de dados categorizados ordinais num enfoque de modelos lineares generalizados. Estes modelos podem, não só, descrever as relações entre a variável resposta de categorias ordinais e as variáveis explicativas, como também, permitem medir esta relação através das estimativas e interpretação dos parâmetros em termos da razão de chances. Além disso, apresentam vantagens em relação aos modelos usuais por serem modelos mais parcimoniosos e de fácil interpretação, levando a um maior poder nos testes para 
independência.

Algumas dificuldades surgem na escolha das categorias de resposta. Anderson \& Philips (1981) alertaram para os problemas que surgem na prática e que afetam o tipo de modelo requerido. Um deles é o tipo de variável categorizada ordinal. O autor citou dois tipos: o primeiro, está diretamente relacionado com a variável contínua subjacente, ou seja, a categorização de uma variável contínua em classes intervalares; o segundo tipo é aquele em que se atribuem escores para caracterizar a variável nominal em categorias ordinais. Os erros tendem a ser maiores para o segundo tipo de categorização.

É importante também identificar quando duas categorias de resposta são indistinguíveis, o que permite combinar categorias de resposta. Por exemplo, numa avaliação de uma enfermidade, pode-se classificar o paciente de acordo com o tratamento recebido como: pior, igual ou melhor. As duas primeiras classificações podem ser indistinguíveis com relação ao tratamento, porém a combinação (pior+igual) pode ser distinguível com relação a "melhor". Anderson \& Philips (1981), porém, aconselharam a não combinar categorias. No entanto, McCullagh \& Nelder (1989) argumentaram que o único efeito em combinar categorias deve ser o de perda na eficiência na estimação dos parâmetros. Para contornar o problema de distinguibilidade, Anderson (1984) apresentou o modelo "estereótipo" ( "stereotype ordered regression model") que requer a inclusão de um parâmetro que descreva a distinguibilidade e ordem das categorias.

Holtbrüigge \& Schumacher (1991) compararam o modelo de Anderson com o modelo de chances proporcionais na análise de um experimento clínico no tratamento de pequenas células de câncer de pulmão. Os resultados indicaram que as estimativas são menos viesadas no modelo de chances proporcionais, porém no modelo "estereótipo" uma melhoria pode ser obtida se as categorias adjacentes são combinadas.

Ashby et al. (1986) compararam alguns procedimentos utilizados para a combinação de categorias adjacentes e mostraram que os valores obtidos pelos 
procedimentos de qualidade de ajuste auxiliam na determinação das categorias adjacentes que podem ser combinadas proporcionando uma melhor qualidade do ajuste. Os referidos autores acrescentaram ainda que a combinação ótima para $k$ categorias é aquela que minimiza o quadrado médio entre categorias. Usaram a estatística de Wald $\left(\hat{\beta}^{\prime} V^{-1} \hat{\beta}\right)$ para a comparação dos modelos fazendo combinações de categorias. $\mathrm{O}$ parâmetro $\beta$ é estimado para cada uma das $k-1$ junções e $\mathrm{V}$ é a matriz de variância de $\hat{\beta}$ obtida a partir da inversa da matriz de informação.

Em algumas situações, porém, torna-se necessária a combinação ou junção de categorias da variável resposta. Quando o tamanho da amostra é pequeno ou, até mesmo quando é grande, mas o número de caselas também o é, ocorrem frequências muito baixas ou caselas vazias na tabela de frequências. Estas tabelas são chamadas Tabelas Esparsas, cuja ocorrência é comum em tabelas com muitas variáveis ou com variáveis com vários níveis de resposta. Agresti (1996) definiu dois tipos de caselas vazias: zeros amostrais e zeros estruturais. O primeiro caso ocorre quando teoricamente é possível ter observações na casela, mas devido ao tamanho insuficiente da amostra ocorrem zeros; o segundo tipo ocorre quando, na situação prática do problema, teoricamente não é possível encontrar observação que satisfaça às condições da casela.

Zeros amostrais são mais comuns e afetam as estimativas de MV dos parâmetros dos modelos, podendo ocorrer estimativas infinitas, ou seja, o processo iterativo não converge. Problemas de tabelas esparsas e caselas vazias provocam estimadores viesados e estatísticas de qualidade de ajuste que não garantem uma boa aproximação com a distribuição qui-quadrado.

Uma das alternativas sugeridas por McCullagh (1980) para evitar zeros e reduzir o viés é a de adicionar uma constante $(1 / 2)$ às contagens. Outra alternativa já mencionada é a de combinar categorias adjacentes, porém, de tal forma que haja pouca perda de informação.

Atualmente, com as melhorias alcançadas em termos computacionais, já se pode contar com testes desenvolvidos através de métodos exatos para amostras 
pequenas e métodos Bayesianos para dados esparsos (Bishop et al., 1975) e (Agresti, 1990).

Embora as estimativas de MV possam ser obtidas através de uma vasta quantidade de programas computacionais estatísticos, até o presente, estes programas ainda são limitados em termos de medidas de qualidade do ajuste e diagnósticos.

Para o caso de uma resposta binária, muitos métodos para medir a qualidade do ajuste foram propostos e implementados nos programas computacionais. Tsiatis (1980) e Hosmer \& Lemeshow (1980) basearam-se na noção de dividir os elementos em grupos ou regiões e, através do quadrado das distâncias entre o valor observado e esperado destas regiões ou partições, medir o ajuste do modelo. Hosmer \& Lemeshow (1980) propuseram esta divisão com base nos percentis das probabilidades preditas a partir do modelo de regressão logística, porém, não se estendia a variáveis respostas discretas com mais de dois níveis. Lipsitz et al. (1996) propuseram uma extensão deste teste aos modelos com resposta ordinal multinomial e, através de um estudo de simulação, compararam-no com outros testes para a verificação das propriedades de amostras pequenas apresentando resultados muito próximos.

Os modelos log-linear e "logit", apresentados por Agresti (1984), assumem que a variância da resposta é constante sobre o intervalo dos valores dos parâmetros. Na prática, no entanto, é comum encontrar dados cuja variância cresce com a média. Wolfe (1996) contemplou, em sua macro ORDINAL desenvolvida no GLIM4, estes modelos mais complexos que envolvem parâmetro de escala, tais como os discutidos por McCullagh (1989), Cox (1995) e Kijewski et al. ${ }^{2}$. Ekholm \& Palmgren (1988) mostraram como ajustar modelos com "logit" cumulativo no GLIM4, usando a técnica de ajuste de modelos não-lineares.

Outro problema que surge no ajuste de modelos para dados de contagens é o de situações em que o número de variáveis explicativas é grande, surgindo

\footnotetext{
${ }^{2}$ KIJEWSKI, M.; SWENSSON, R.; JUDY, P. Analysis of rating data from multiplealternative tasks. Journal of Mathematical Psychology, 33, p.428-451, 1989.
} 
a necessidade de se fazer uma seleção de variáveis. Hosmer \& Lemeshow (1989) sugeriram dois passos a seguir:

1. iniciar o processo de seleção com a análise univariada cuidadosa de cada variável através de tabelas de contingência e verificar as variáveis que apresentam um nível moderado de associação;

2. proceder a uma análise de regressão múltipla, envolvendo as variáveis escolhidas no primeiro passo, que pode ser feita através do método "stepwise" no qual as variáveis para o modelo podem ser selecionadas tanto por inclusão ( "forward") quanto por exclusão ( "backward") sequencial.

Diante da necessidade crescente de adoção de técnicas estatísticas mais adequadas e refinadas, a literatura referente à análise de dados categorizados ordinais vem sendo desenvolvida com aplicações cada vez mais abrangentes nas áreas do conhecimento.

A análise de dados categorizados ordinais, através do método de mínimos quadrados reponderados iterativamente para a estimação de máxima verossimilhança dos parâmetros, exige uma parte computacional bastante intensa e, atualmente, alguns pacotes estatísticos vêm implementando macros para desenvolvêla. Há necessidade, porém, de serem criadas macros mais específicas e abrangentes no sentido de contemplarem mais modelos, análise gráfica e de resíduos. Friendly ${ }^{3}$ sugeriu algumas adaptações nos procedimentos do SAS através de macros para apresentação gráfica da análise de dados categorizados, disponíveis na INTERNET.

\footnotetext{
${ }^{3}$ FRIENDLY, M. Categorical data analysis with graphics. SCS SHORT COURSE, http://pascal.math. yorku.ca/SCS/Courses/grcat, CONSULTADO EM ABRIL DE 1998).
} 
No que se refere à parte de estimação de parâmetros dos modelos para análise de dados categorizados ordinais, podem-se citar os seguintes programas computacionais:

\section{GLIM4}

O programa GLIM4 dispõe da macro ORDINAL desenvolvida por Wolfe (1996) específica para os modelos com variáveis de natureza ordinal. Os modelos que podem ser ajustados com este conjunto de macros são baseados em probabilidades cumulativas das categorias de resposta, ou modelos com "logit" cumulativo. Outros modelos mais complexos, como os que contêm parâmetro de escala, também podem ser ajustados, inclusive com a escolha da função de ligação do tipo: logit, probit ou complemento log-log. Ainda engloba modelos com "logit" cumulativo usando técnicas de ajuste de modelos não-lineares.

Outro recurso da macro ORDINAL é dispor da macro INDI_DAT que permite ao usuário entrar com os dados por indivíduo, além da forma usual de tabelas de contingência. A macro ORDINAL ${ }^{4}$ encontra-se disponível na INTERNET. Instruções sobre o uso do programa GLIM4 podem ser encontradas em Aitkin et al. (1989) e Healy (1988).

\section{SAS}

O sistema SAS é amplamente utilizado por profissionais das mais diversas áreas do conhecimento devido à facilidade no uso dos procedimentos, o que permite desde análises mais simples até técnicas estatísticas mais complexas.

\footnotetext{
${ }^{4}$ WOLFE: http://www. maths.soton.ac.uk. (consultado em maio de 1998)
} 
Em termos da análise de dados categorizados o sistema apresenta vários procedimentos, tais como:

\section{(a) PROC FREQ}

Este procedimento auxilia na criação de tabelas de contingência, desenvolvendo testes como qui-quadrado de Pearson, coeficiente de correlação de Spearman, razão de verossimilhança e os testes de Mantel-Haenszel e Fisher. Também fornece algumas medidas de associação, tais como: gamma, Kendall's tau-b, Stuart's tau-c, Somers' D, lambda, e para tabelas $2 \times 2$, razões de chances, razões de risco e respectivos intervalos de confiança. A opção EXACT fornece o teste exato de Fisher para tabelas de maiores dimensões (SAS, versão 6.03, 1988).

\section{(b) PROC CATMOD}

Permite uma vasta variedade de modelos para análise de dados categorizados. Tanto os modelos log-lineares quanto os modelos "logit" podem ser ajustados. Friendly ${ }^{5}$ apontou algumas diferenças entre o PROC CATMOD e o PROC LOGISTIC para o ajuste do modelo logit, que são (SAS, versão $6.03,1988$ ):

i. no PROC CATMOD as variáveis independentes podem ser categorizadas ou contínuas, qualitativa ou quantitativa enquanto que no PROC LOGISTIC as variáveis independentes devem ser quantitativas;

ii. para utilizar variáveis categorizadas nominais, devem-se construir variáveis dicotômicas;

iii. a disposição dos dados no arquivo difere de um procedimento para outro, porém, as saídas contêm as mesmas informações dispostas de formas diferentes.

${ }^{5}$ FRIENDLY, M. ibid. 
(c) PROC LOGISTIC

Este procedimento ajusta modelos de regressão logística para dados binários ou de resposta ordinal, permitindo que o usuário faça a escolha da função de ligação, como: "logit" cumulativo, probit ou complemento $\log -\log$. O único inconveniente é que o diagnóstico da regressão só é possível para dados binários. O método de estimação utilizado é o de máxima verossimilhança e considera o modelo de chances proporcionais como "default" (SAS, versão 6.09, 1993).

Outras informações sobre o uso do PROC LOGISTIC e PROC CATMOD para modelos logísticos multinomiais podem ser encontradas na homepage como parte do curso de Modelos Lineares Generalizados oferecido por Hanneman ${ }^{6}$.

\section{(d) PROC GENMOD}

Recentemente introduzido na versão 6.11 (SAS, 1993), este procedimento ajusta os modelos lineares generalizados abrangendo tanto modelos lineares clássicos com erros com distribuição normal, modelos logístico e probit para dados binários e modelos log-lineares para dados multinomiais. Outros modelos estatísticos podem ser formulados como os modelos lineares generalizados desenvolvidos por Nelder \& Wedderburn (1972), através da escolha da função de ligação e da distribuição de probabilidade da resposta. Mais informações sobre o seu uso, inclusive com aplicações, encontram-se disponíveis na StatLib ${ }^{7}$

Além destes programas citam-se o SPSS (LOGLINEAR) e o GENCAT e, mais recentemente, o MINITAB v.11 que incorporou um módulo específico para dados categorizados ordinais.

\footnotetext{
${ }^{6}$ HANNEMAN, R. Ordered logit and probit models with PROC LOGIST and PROC Probit. Generalized linear Models Course. University of California, Riverside, http://wizard.ucr.edu/ rhannema/glm/ologit/html, (CONSULTADO EM ABRIL DE 1998).

${ }^{7}$ STATLIB: http://lib.stat. cmu.edu/datasets/agresti ou statlib@lib. stat. cmu .edu .
} 


\section{MATERIAL}

Como aplicações dos modelos para dados categorizados ordinais, serão utilizados dois conjuntos de dados da área de Agropecuária referentes a doenças manifestadas em plantas e animais e suas relações com outras variáveis observadas. Em ambos os exemplos, as variáveis respostas caracterizam-se por serem categorizadas ordinais e requerem o uso de modelos específicos para a análise que serão apresentados em Métodos.

\subsection{Aplicação em Fitopatologia}

A fim de identificar as associações entre a característica genotípica de dois marcadores moleculares e a resistência em milho à Puccinia sorghi, agente causal da ferrugem comum, foi conduzido um experimento na Estação Experimental da Agroceres, em Santa Cruz das Palmeiras (São Paulo, em 1997). Este estudo é parte de um projeto em andamento cujos resultados parciais foram publicados por Camargo et al., (1998). A obtenção dos dados consistiu de duas etapas: uma em laboratório (genotipagem) e outra no campo (avaliação da doença).

Utilizou-se a técnica de mapeamento por meio de marcadores moleculares de genes que controlam determinada característica quantitativa que consiste na genotipagem, para loci marcadores, de indivíduos de uma progênie segregante e avaliação fenotípica destes indivíduos (ou de suas progênies) para a característica em estudo, ou seja, para a característica quantitativa do loci (QTL).

A estratégia de mapeamento consistiu da genotipagem de 97 plantas da segregação F2, resultantes do cruzamento entre duas linhas endocriadas, uma resistente (L10) e outra suscetível (L20), com dois loci marcadores micro-satélites, 
um do cromossomo 2 (bngl166) e outro do cromossomo 8 (bngl699) (Taramino \& Tingey, 1996): Usou-se a notação 1 e 2 para denotar alelos oriundos de L10 e L20, respectivamente. Estes marcadores determinam uma posição no cromossomo (locus) que engloba vários genes e, através da Reação de Polimerase em Cadeia (PCR) é possível a ampliação dos micro-satélites para a identificação dos primers, . que são sequências de DNA. Estas plantas F2 foram auto-polinizadas de forma a gerar progênies F3, que foram avaliadas para a resistência à Puccinia sorghi num experimento de campo.

O experimento de campo consistiu de um delineamento em blocos completos casualizados em três blocos, com esquema fatorial de tratamentos com interação, e as parcelas constituídas por 10 plantas de cada progênie desenvolvidas num sulco de $2,5 \mathrm{~m}$ por $0,8 \mathrm{~m}$. As plantas foram naturalmente infectadas e uma avaliação visual do grau de severidade da doença foi feita através de uma escala padrão de notas de 1 a 9 de acordo com a área da folha afetada pela doença, sendo que 1 corresponde a nenhum sintoma e 9 corresponde a mais de $75 \%$ da área da folha afetada (Figura 1). 

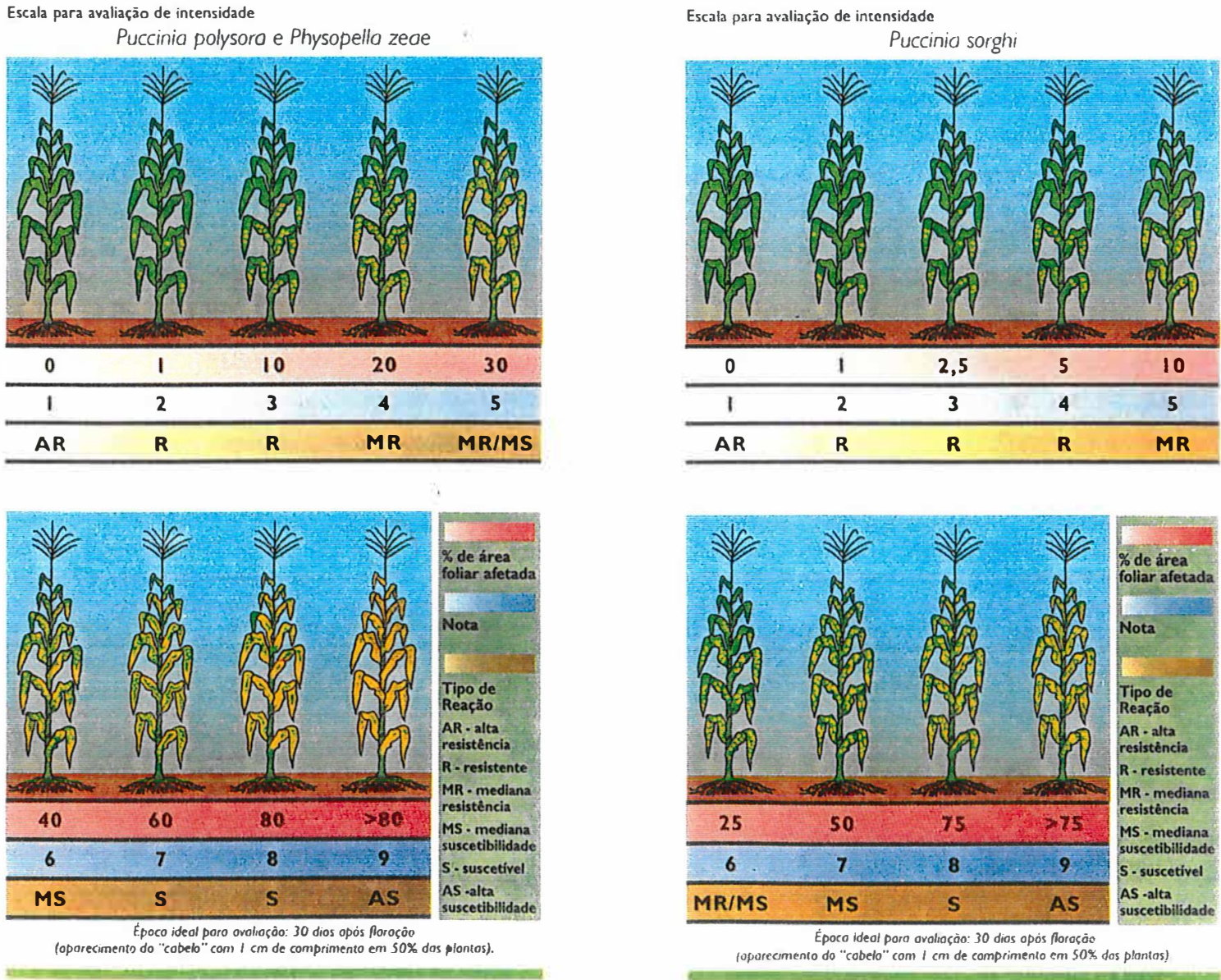

Figura 1: Grau de severidade da doença - Escala padrão. 


\subsection{Aplicação em Zootecnia}

Na suinocultura, os problemas sanitários constituem um fator de preocupação constante entre produtores e técnicos, tanto pela perda de animais e gastos com medicamentos, como pela redução nos índices técnicos. Desta forma, tornam-se necessários estudos que visem identificar e controlar os chamados fatores de risco associados às doenças de leitões. Um dos problemas sanitários mais frequentes que afetam os leitões lactentes e na desmama é a diarréia (Barioni, 1995).

O interesse deste estudo, portanto, é o de verificar quais as variáveis que, uma vez presentes em um sistema de produção, aumentam a probabilidade do aparecimento e desenvolvimento de determinados problemas patológicos nas granjas. A identificação dos fatores de risco pode melhorar a performance dos animais permitindo visualizar as condições mais adequadas de criação.

Com o intuito de caracterizar o máximo de informação possível do ecossistema do suíno na maternidade, aplicou-se um questionário em 85 granjas, selecionadas ao acaso, situadas na região Oeste de Santa Catarina e no Sudoeste do Paraná, no período compreendido entre os anos de 1988 e 1992 . Este questionário consistia de 158 variáveis (quantitativas e qualitativas) que caracterizavam o problema patológico estudado, diarréia, totalizando 442 leitegadas. Este arquivo de dados continha informações referentes ao leitão, à diarréia, à granja, à leitegada, à temperatura, ao manejo e ao puerpério (período anterior e posterior ao parto), e foram gentilmente cedidas pelo pesquisador, em acordo com a EMBRAPA-Suínos e Aves de Concórdia (SC).

Este tipo de levantamento de dados, portanto, é proveniente de um estudo observacional, reunindo várias características dos animais e das condições em que os mesmos são mantidos para, com isto, possibilitar a determinação das interrelações das variáveis que compõem o sistema com a ocorrência de determinadas patologias, tais como a em estudo, a DIARRÉIA. Esta variável resposta corresponde a categorias de respostas ordinais formadas através do número de dias em que os leitões apresentaram diarréia no período de 27 dias de acordo com o seguinte critério: 
DIAR1 - ausência de diarréia;

DIAR2 - de 1 a 5 dias com diarréia, considerada como diarréia moderada e

DIAR3 - mais de 5 dias com diarréia, considerada como diarréia intensa.

As 158 variáveis combinadas de acordo com critérios pré-estabelecidos, resultaram em 40 novas variáveis, apresentadas nas Tabelas 1, 2 e 3. As variáveis quantitativas foram categorizadas para o desenvolvimento da análise de correspondência feita por Barioni (1995) e, para efeito da análise de dados categorizados ordinais, considerou-se a mesma classificação do pesquisador.

Tabela 1: Descrição das variáveis explicativas categorizadas nominais.

\begin{tabular}{|c|c|c|c|c|}
\hline \multirow[t]{2}{*}{ Descrição das Variáveis } & \multirow[t]{2}{*}{ Sigla } & \multicolumn{3}{|c|}{ Classes } \\
\hline & & 0 & 1 & 2 \\
\hline Vacina contra colibacilose & $\mathrm{VC}$ & Sim & Não & \\
\hline $\begin{array}{l}\text { Assist. aos leitões } \\
\text { com corte de dentes e } \\
\text { desinfec. do umbigo }\end{array}$ & $\mathrm{AP}$ & Sim & Não & \\
\hline $\begin{array}{l}\text { Vazio sanitário } \\
\text { (dias) }\end{array}$ & VS & Contínuo & $\geq 1 \leq 5$ & $>5$ \\
\hline Aleitamento em grupo & AG & Sim & Não & \\
\hline Tipo de piso & $\mathrm{TP}$ & Compacto & $\begin{array}{l}\text { Semi- } \\
\text { ripado }\end{array}$ & $\begin{array}{l}\text { Tot. } \\
\text { ripado }\end{array}$ \\
\hline Presença de forro & $\mathrm{PF}$ & Sim & Não & \\
\hline Presença escamoteador & $\mathrm{PE}$ & Sim & Não & \\
\hline Fonte suplem. de calor & FSC & Sim & Não & \\
\hline $\begin{array}{l}\text { Presença da tampa } \\
\text { no escamoteador }\end{array}$ & PTE & Sim & Não & \\
\hline $\begin{array}{l}\text { Parasitismo nas fềmeas } \\
\text { e nos leitões }\end{array}$ & PAR & Sim & Não & \\
\hline Problema no parto & PNP & Sim & Não & \\
\hline Tratamento com oxitocina & $\mathrm{TCO}$ & $\operatorname{Sim}$ & Não & \\
\hline $\begin{array}{l}\text { Tratamento com } \\
\text { antibiótico }\end{array}$ & TRA & Sim & Não & \\
\hline
\end{tabular}

Fonte: Barioni (1995) 
Tabela 2: Descrição das variáveis explicativas categorizadas ordinais.

\begin{tabular}{|c|c|c|c|c|}
\hline \multirow[t]{2}{*}{ Descrição das Variáveis } & \multirow[t]{2}{*}{ Sigla } & \multicolumn{3}{|c|}{ Classes } \\
\hline & & 1 & 2 & 3 \\
\hline Parecer sobre higiene & PSH & Ruim & Regular & Bom \\
\hline Estado nutricional das porcas (pontos) & NUT & Ruim & Regular & Bom \\
\hline Altura do pé direito & $\mathrm{PD}$ & $<2,8$ & $\geq 2,8 \leq 3,5$ & \\
\hline $\begin{array}{l}\text { Abertura de janelas e portas externas } \\
\text { por área do escamoteador (\%) }\end{array}$ & PAJ & $\leq 5$ & $>5 \leq 20$ & $>20$ \\
\hline Área do escamoteador $\left(m^{2}\right)$ & ARE & $=0,0$ & $>0 \leq 0,7$ & $>0,7$ \\
\hline Ordem do parto & ODP & $=0$ & $>1 \leq 4$ & $>4$ \\
\hline$N^{o}$ leitões nascidos vivos & NLV & $\leq 8$ & $>8 \leq 11$ & $>11$ \\
\hline$N^{o}$ leitões desmamados aos 35 dias & NLD & $\leq 8$ & $>8 \leq 11$ & $>11$ \\
\hline Volume de ar por leitegada $\left(m^{3}\right)$ & VAL & $\leq 20$ & $>20 \leq 27$ & $>27$ \\
\hline$N^{o}$ celas parideiras & NCP & $\leq 10$ & $>10$ & \\
\hline Área da cela parideira $\left(m^{2}\right)$ & ASP & $\leq 3,96$ & $>3,96$ & \\
\hline$N^{o}$ leitegadas presentes & NLP & $\leq 10$ & $>10 \leq 15$ & $>15$ \\
\hline $\begin{array}{l}\text { Área total disponível por } \\
\text { leitegada }\left(m^{2}\right)\end{array}$ & ADISP & $<4$ & $\geq 4$ & \\
\hline$N^{o}$ dias com amplitude térmica $\geq 6^{\circ} C^{*}$ & DAMPL16 & $\leq 7$ & $>7 \leq 14$ & $>14$ \\
\hline $\begin{array}{l}N^{o} \text { dias com temperatura } \\
\text { máxima } \geq 28^{\circ} C^{*}\end{array}$ & DTMAX28 & $\leq 10$ & $>10$ & \\
\hline $\begin{array}{l}N^{o} \text { dias com temperatura } \\
\text { mínima } \leq 16^{\circ} C^{*}\end{array}$ & DTMIN16 & $\leq 5$ & $>5$ & \\
\hline $\begin{array}{l}N^{o} \text { dias com temperatura variando de } \\
18 \text { a } 24^{\circ} C^{*} \text { (conforto térmico) }\end{array}$ & CT1824 & $=0$ & $\geq 1$ & \\
\hline Mćdia das tcmpcraturas máximas $\left({ }^{\circ} \mathrm{C}\right)^{*}$ & MTMAX & $<28$ & $\geq 28$ & \\
\hline Média das temperaturas mínimas $\left({ }^{\circ} C\right)^{*}$ & MTMIN & $\leq 16$ & $>16$ & \\
\hline Amplitude térmica média $\left({ }^{\circ} C\right)^{*}$ & MAMPLI & $\leq 6$ & $>6$ & \\
\hline Patologia do parto (pontos) & PATOPAR & $\leq 1$ & $>1 \leq 6$ & $>6$ \\
\hline
\end{tabular}

* No interior da maternidade, período de 21 dias pós parto

Fonte: Barioni (1995) 


\begin{tabular}{l|c}
\multicolumn{2}{l}{ Tabela 3: Descrição das variáveis suplementares (contínuas)._- Sigla } \\
\hline Descrição das Variáveis & PMN \\
\hline Peso médio da leitegada no nascimento (kg) & PMD35 \\
Peso médio de leitões/leitegada* & GPM35 \\
Ganho de peso médio diário dos leitões & \\
por leitegada* (g) & \\
Coef. de variação do peso leitões/leitegada* (\%) & CV35 \\
Taxa dc mortalidadc por granja* & STMORTE \\
\hline
\end{tabular}

* No interior da maternidade, período de 21 dias pós parto Fonte: Barioni (1995)

O autor alerta para se ter cuidado na análise estatística e não cometer o erro de explicar a ocorrência de uma doença pelos seus próprios sintomas, por isso, consideraram-se as variáveis apresentadas na Tabela 3 como variáveis suplementares, sendo assim, não se justifica a inclusão das mesmas no modelo como variáveis explicativas. 


\section{MÉTODOS}

\subsection{Dados Categorizados}

A análise de dados categorizados consiste no estudo de variáveis respostas cuja escala de medida é dada através de um conjunto de categorias que podem ser do tipo:

Escala Nominal onde as categorias podem ser permutáveis. Para este tipo de classificação é irrelevante a ordem das categorias na análise. Exemplos deste tipo de variável são: tipos de vegetação, estações climáticas, genótipos de plantas, raças de animais.

Escala Intervalar nas quais as categorias são ordenadas em classes numéricas que são representadas por escores que podem ser a média, a mediana ou o ponto médio. São exemplos: os níveis de pressão sanguínea, renda familiar, faixa etária.

Escala Ordinal cujas categorias descrevem uma ordenação natural dos seus níveis. Este tipo de variável é de vasta aplicação em diversas áreas do conhecimento, como nas Ciências Sociais, Biomédicas, Engenharias e Ecologia, dentre outras, sendo muito utilizada em estudos de melhoramento animal e vegetal. São exemplos: o grau de severidade de doenças em plantas segundo a área da planta afetada ou pelo número de manchas (notas); classificação de árvores segundo o número de galhos e o tipo de inserção (notas); classificação de produtos no mercado (péssimo, ruim, regular, bom, ótimo), classe social (baixa, média, alta), etc. 
A distinção entre escala nominal e ordinal, no entanto, nem sempre é muito clara nas aplicações. Algumas variáveis têm características bem definidas e que se enquadram perfeitamente em uma ou em outra classificação, porém, existem variáveis difíceis de classificar. Por exemplo, cor de cabelo ou de olhos pode ser considerada ordinal se existir uma clara conexão com o espectro eletromagnético, caso contrário, é melhor considerá-la como nominal.

O objetivo da análise de dados categorizados ordinais é verificar como determinadas variáveis explicativas (ou independentes) influenciam a classificação de uma (univariada) ou mais variáveis (multivariada) respostas ordinais. As variáveis explanatórias podem ser classificadas como nominais, e serão tratadas como fatores, ou ordinais, consideradas como covariáveis.

As observações consistem de contagens ou frequências dispostas em tabelas de contingência multinomiais formada através da classificação cruzada das variáveis onde, na maioria das aplicações, uma das variáveis é tratada como variável resposta e as demais como explanatórias.

\subsection{Tabelas de Contingência}

A disposição das frequências em tabelas de contingência surgiu da necessidade de medir o grau de associação entre as variáveis.

\subsubsection{Notação e Definições}

Sejam X e Y duas variáveis categorizadas com $\mathbf{r}$ e c níveis, respectivamente, portanto existirão rc combinações possíveis de classificação, ou seja, cada casela na tabela de contingência corresponderá a um dos rc resultados. As notações para frequências e proporções observadas são apresentadas nas Tabelas 4 e 5 , 
Tabela 4: Notação para as frequências observadas e totais marginais.

\begin{tabular}{ccccccc}
\hline Linhas & \multicolumn{4}{c}{ Colunas } & & \\
& 1 & $\ldots$ & $\mathrm{j}$ & $\ldots$ & $\mathrm{c}$ & \\
\hline 1 & $n_{11}$ & $\ldots$ & $n_{1 j}$ & $\ldots$ & $n_{1 c}$ & $n_{1+}$ \\
$\ldots$ & $\ldots$ & $\ldots$ & $\ldots$ & $\ldots$ & $\ldots$ & $\ldots$ \\
$\mathrm{i}$ & $n_{i 1}$ & $\ldots$ & $n_{i j}$ & $\ldots$ & $n_{i c}$ & $n_{i+}$ \\
$\ldots$ & $\ldots$ & $\ldots$ & $\ldots$ & $\ldots$ & $\ldots$ & $\ldots$ \\
$\mathrm{r}$ & $n_{r 1}$ & $\ldots$ & $n_{r j}$ & $\ldots$ & $n_{r c}$ & $n_{r+}$ \\
\hline Totais & $n_{+1}$ & $\ldots$ & $n_{+j}$ & $\ldots$ & $n_{+c}$ & $\mathrm{~N}$ \\
\hline
\end{tabular}

Tabela 5: Notação para as proporções observadas.

\begin{tabular}{ccccccc}
\hline Linhas & \multicolumn{4}{c}{ Colunas } & \multicolumn{3}{c}{ Totais } \\
& 1 & $\ldots$ & $\mathrm{j}$ & $\ldots$ & $\mathrm{c}$ & \\
\hline 1 & $p_{11}$ & $\ldots$ & $p_{1 j}$ & $\ldots$ & $p_{1 c}$ & $p_{1+}$ \\
$\ldots$ & $\ldots$ & $\ldots$ & $\ldots$ & $\ldots$ & $\ldots$ & $\ldots$ \\
$\mathrm{i}$ & $p_{i 1}$ & $\ldots$ & $p_{i j}$ & $\ldots$ & $p_{i c}$ & $p_{i+}$ \\
$\ldots$ & $\ldots$ & $\ldots$ & $\ldots$ & $\ldots$ & $\ldots$ & $\ldots$ \\
$\mathrm{r}$ & $p_{r 1}$ & $\ldots$ & $p_{r j}$ & $\ldots$ & $p_{r c}$ & $p_{r+}$ \\
\hline Totais & $p_{+1}$ & $\ldots$ & $p_{+j}$ & $\ldots$ & $p_{+c}$ & 1 \\
\hline
\end{tabular}

onde:

$n_{i j}$ - número de observações na casela da classificação cruzada da i-ésima linha e j-ésima coluna;

$\mathbf{N}$ - número de observações em toda a amostra, isto é, $N=\sum_{i, j} n_{i j}$;

$p_{i j}$ - proporção amostral correspondente à casela $i j$, sendo, $p_{i j}=\frac{n_{i j}}{N}$ (distribuição conjunta amostral); 
$p_{i+}$ e $\left[p_{+j}\right]$ - distribuições marginais das linhas e colunas, respectivamente, com

$$
\begin{aligned}
p_{i+}=\sum_{j} p_{i j} & =\frac{n_{i+}}{N} \quad p_{+j}=\sum_{i} p_{i j}=\frac{n_{+j}}{N} \text { com } \\
\sum_{i, j} p_{i j} & =1, \quad \sum_{i} p_{i+}=\sum_{j} p_{+j}=1 .
\end{aligned}
$$

As distribuições condicionais serão denotadas por:

$$
\begin{array}{rlrl}
p_{i(j)} & =\frac{n_{i j}}{n_{i+}} & \text { com } & n_{i+}=\sum_{j} n_{i j} \\
p_{j(i)}=\frac{n_{i j}}{n_{+j}} & \text { com } & n_{+j}=\sum_{i} n_{i j}
\end{array}
$$

Esta notação corresponde aos dados amostrais; no caso de proporções populacionais o termo p será substituído pela letra grega $\pi$. A Tabela 6 ilustra as proporções populacionais para o caso bidimensional.

Tabela 6: Notação para as probabilidades conjunta, condicional e marginal.

\begin{tabular}{cccc}
\hline Linhas & \multicolumn{2}{c}{ Colunas } & Total \\
& 1 & 2 & \\
\hline 1 & $\pi_{11}$ & $\pi_{12}$ & $\pi_{1+}$ \\
& $\left(\pi_{1(1)}\right)$ & $\left(\pi_{2(1)}\right)$ & $(1.0)$ \\
2 & $\pi_{21}$ & $\pi_{22}$ & $\pi_{2+}$ \\
& $\left(\pi_{1(2)}\right)$ & $\left(\pi_{2(2)}\right)$ & $(1.0)$ \\
\hline Total & $\pi_{+1}$ & $\pi_{+2}$ & 1.0 \\
\hline
\end{tabular}

As medidas descritivas para classificação cruzada em variáveis ordinais são às vezes expressas em termos de função de distribuição. Seja:

$$
\gamma_{i j}=\sum_{a \leq i \leq j} \sum_{b \leq j} \pi_{a b}, \quad i=1, \ldots, r \quad \text { e } \quad j=1, \ldots, c
$$

a função de distribuição conjunta na população, ou seja, $\gamma_{i j}$ é a probabilidade de classificação nas primeiras i linhas e primeiras j colunas, então: 


$$
\gamma_{i}^{X}=\sum_{a \leq i} \pi_{a+}=\gamma_{i c} \quad \text { e } \quad \gamma_{j}^{Y}=\sum_{b \leq j} \pi_{+b}=\gamma_{r j}
$$

são as funções de distribuição marginais e $\gamma_{j(i)}=\sum_{b \leq j} \pi_{b(i)}$ é a função de distribuição condicional que fornece a probabilidade de classificação em uma das primeiras $j$ colunas dada a classificação na linha i.

\subsubsection{Esquemas de Amostragem}

Dobson (1990) e Fienberg (1994) descrevem os três modelos de amostragem comumente utilizados para análise de dados categorizados:

\section{POISSON}

Observa-se um conjunto de processos Poisson, um para cada casela na tabela de classificação cruzada, onde nenhuma restrição sobre as frequências $n_{i j}$ ou sobre os parâmetros é imposta, ou seja, sem nenhum conhecimento a priori do número total de observações. O uso deste modelo para tabelas de contingência foi primeiro sugerido por Fisher (1950). Assim, para uma tabela tridimensional, por exemplo, na qual as contagens das $r c l$ caselas $\left(n_{i j k}\right)$ têm distribuições independentes Poisson com frequências esperadas $m_{i j k}$, a função de probabilidade conjunta para este modelo é:

$$
P\left(n_{i j k}\right)=\prod_{i, j, k} \frac{m_{i j k}^{n_{i j k}} e^{-m_{i j k}}}{n_{i j k} !}
$$

e a frequência total $N=n_{+++}$, tem distribuição Poisson com média $m_{+++}=$ $\sum_{i, j, k} m_{i j k}$.

\section{MULTINOMIAL}

Considera-se uma determinada amostra de tamanho $\mathrm{N}$ e classifica-se cada um dos indivíduos da amostra de acordo com as categorias cruzadas das variáveis em estudo. A função de probabilidade conjunta do modelo multinomial é:

$$
P\left(n_{i j k} / N\right)=\frac{N !}{\prod_{i, j, k}} \frac{n_{i j k} !}{i, j, k} p_{i j k}^{n_{i j k}}
$$


onde $\sum_{i, j, k} p_{i j k}=1$. Os valores esperados de $\left\{n_{i j k}\right\}$ são $\left\{N p_{i j k}\right\}$. Pode-se verificar que se $\left\{n_{i j k}\right\}$ foi gerada de um esquema de amostragem Poisson dada a restrição de que $n_{+++}=N$, então é uma Poisson com função de probabilidade (2) onde $p_{i j k}=\frac{m_{i j k}}{m_{+++}}$.

\section{PRODUTO MULTINOMIAL}

O terceiro modelo de amostragem ocorre em situações onde uma ou mais variáveis podem ser consideradas como variáveis explanatórias e as demais variáveis respostas. Então, para cada combinação de variáveis explanatórias tem-se um tamanho amostral fixo, e a classificação cruzada de cada amostra de acordo com a variável resposta tem distribuição multinomial. Por exemplo, suponha um total fixo para a terceira variável $\mathrm{Z}, n_{++k}$ e seja $P_{i j k}$ a probabilidade de uma observação ser classificada na i-ésima categoria da variável 1 e na j-ésima categoria da variável 2 dado que pertença à k-ésima categoria da variável 3 (ou seja, $P_{i j k}=\frac{p_{i j k}}{p_{+}}$). Então a função de probabilidade conjunta do esquema amostral produto-multinomial é:

$$
P\left(n_{i j k} / n_{++k}\right)=\prod_{k} \frac{n_{++k} !}{\prod_{i j} n_{i j k} !} \prod_{i, j} P_{i j k}^{n_{i j k}} .
$$

Assim têm-se amostras multinomiais independentes para a k-ésima categoria da variável Z. Os valores esperados de $\left\{n_{i j k}\right\}$ para este modelo são $\left\{n_{++k} P_{i j k}\right\}$. Poder-se-ia fixar um conjunto de totais marginais bidimensionais, ou seja, $\left\{n_{+j k}\right\}$, e obter um esquema produto-multinomial com amostras multinomiais independentes para cada combinação coluna-estrato. Observa-se, assim, que a função de probabilidade produto-multinomial é também uma função de probabilidade condicional para $\left\{n_{i j k}\right\}$ gerada por um esquema amostral multinomial dado $\left\{n_{++k}\right\}$.

Dada a equivalência das distribuições 1,2 e 3, as estimativas de MV para os três esquemas de amostragem citados possuem as mesmas propriedades assintóticas. 
$\mathrm{Na}$ amostragem multinomial para tabela bidimensional, as estimativas de MV para a proporção marginal da linha $\left\{\pi_{i+}\right\}$ e para a proporção marginal da coluna $\left\{\pi_{+j}\right\}$ são as proporções amostrais correspondentes $\left\{p_{i+}\right\}$ e $\left\{p_{+j}\right\}$, respectivamente.

Sob a suposição de independência das duas variáveis $\pi_{i j}=\pi_{i+} \pi_{+j}$, a estimativa de MV de $\pi_{i j}$ (denotada por $\hat{\pi}_{i j}$ ) é

$$
\hat{\pi}_{i j}=p_{i+} p_{+j}=\frac{n_{i+} n_{+j}}{N^{2}} .
$$

$\mathrm{Na}$ distribuição multinomial, assim como na Poisson, $\left\{m_{i j}\right\}$ representam as frequências esperadas. Se $\left\{n_{i j}\right\}$ têm distribuição amostral multinomial, por exemplo, cada $n_{i j}$ tem distribuição binomial baseada no tamanho amostral $\mathrm{N}$ e probabilidade de sucesso $\pi_{i j}$. Assim, $m_{i j}=E\left(n_{i j}\right)=N \pi_{i j}$. A estimativa de MV de $m_{i j}$, portanto, é:

$$
\hat{m}_{i j}=N \hat{\pi}_{i j}
$$

que sob a suposição de independência é igual a

$$
\hat{m}_{i j}=N p_{i+} p_{+j}=\frac{n_{i+} n_{+j}}{N}, \quad i=1,2 \quad e \quad j=1,2
$$

onde $\left\{\hat{m}_{i j}\right\}$ são as frequências esperadas estimadas para testar a hipótese nula de independência. As $\left\{\hat{m}_{i j}\right\}$ têm os mesmos totais marginais que os dados observados, por exemplo,

$$
\hat{m}_{i+}=\sum_{j} \hat{m}_{i j}=\left(\frac{n_{i+}}{N}\right) \sum_{i} n_{+j}=n_{i+}
$$

\subsubsection{Razão de Chances - ("Odds Ratio")}

Os testes de associação fornecem uma indicação da presença ou não de uma associação entre duas variáveis, mas por si só não acrescentam nenhuma informação a respeito de questões de grande interesse prático como, por exemplo, avaliar o grau de intensidade desta associação.

Uma medida que complementa tais informações é a razão de chances ("odds ratio") que descreve o grau de associação numa tabela de contingência. Por 
exemplo, numa tabela $2 \times 2$, fixada a linha 1 , a chance de a resposta estar na coluna 2 ao invés da coluna 1 é

$$
\Omega_{1}=\frac{\pi_{12}}{\pi_{11}}
$$

da mesma forma, a correspondente na linha 2 é

$$
\Omega_{2}=\frac{\pi_{22}}{\pi_{21}} .
$$

Cada $\Omega_{i}(i=1,2)$ é sempre positiva com valor maior do que 1 se a resposta 2 é mais provável do que 1. A razão destas chances é dada por:

$$
\theta=\frac{\Omega_{2}}{\Omega_{1}}=\frac{\pi_{22} \pi_{11}}{\pi_{12} \pi_{21}}
$$

denominada razão de chances ("odds ratio").

Cada $\Omega_{i}$ pode ser escrito como $\Omega_{i}=\frac{\pi_{2(i)}}{\pi_{1(i)}}$ e assim

$$
\theta=\frac{\left(\pi_{2(2)} / \pi_{1(2)}\right)}{\left(\pi_{2(1)} / \pi_{1(1)}\right)}
$$

quando os parâmetros $\pi_{i j}$ são desconhecidos. O estimador de M.V. de $\theta$ envolve as frequências amostrais e é dado por:

$$
\hat{\theta}=\frac{n_{11} n_{22}}{n_{12} n_{21}}
$$

Se:

$\theta=1$ indica que as duas distribuições condicionais $\left(\pi_{1(1)}, \pi_{2(1)}\right)$ e $\left(\pi_{1(2)}, \pi_{2(2)}\right)$ são idênticas e, portanto, as variáveis são independentes;

$1<\theta<\infty$ indica que os indivíduos na linha 2 estão mais propensos à segunda resposta do que os indivíduos na linha 1;

$0 \leq \theta<1$ indica que os indivíduos na linha 2 estão menos propensos à segunda resposta do que os indivíduos na linha 1. 
A razão de chances é uma função multiplicativa das proporções das caselas. O logaritmo da razão de chances é uma função aditiva, ou seja,

$$
\log \theta=\log \pi_{11}-\log \pi_{12}-\log \pi_{21}+\log \pi_{22}
$$

Esta função é simétrica em torno do valor independente 0 (zero) no sentido de que uma permutação das linhas, ou das colunas, resulta numa mudança de sinal, porém representa o mesmo grau de associação. O estimador de M.V. de $\log \theta$ é $\log \hat{\theta}$.

Sob modelos de amostragem aleatória, $\log \hat{\theta}$ tem distribuição assintoticamente normal (quando $n \rightarrow \infty$ ) em torno de seu valor populacional. Sendo $\log \hat{\theta}$ uma função aditiva e não multiplicativa dos $\left\{n_{i j}\right\}$ sua distribuição tende a convergir mais rapidamente para sua distribuição assintótica do que a distribuição de $\hat{\theta}$. Gart $\&$ Zweiful (1967) sugeriram que a substituição de $\left\{n_{i j}\right\}$ por $\left\{n_{i j}+0,5\right\}$ em $\hat{\theta}$ acarreta uma melhoria no estimador tornando-o menos viesado.

O desvio padrão assintótico de $\log \hat{\theta}$ (Agresti, 1984), denotado por $\sigma(\log \hat{\theta})$, pode ser estimado por:

$$
\hat{\sigma}(\log \hat{\theta})=\sqrt{\frac{1}{n_{11}}+\frac{1}{n_{12}}+\frac{1}{n_{21}}+\frac{1}{n_{22}}} .
$$

Logo, um intervalo de confiança aproximado com coeficiente de confiança $(1-\alpha)$ para $\log (\hat{\theta})$ é dado por:

$$
\log \hat{\theta} \pm z_{\alpha / 2} \hat{\sigma}(\log \hat{\theta})
$$

onde $z_{\alpha / 2}$ é o percentil $(\alpha / 2) .100$ da distribuição normal padrão.

Em tabelas de maiores dimensões, cada par de linhas (i e r) e cada par de colunas (j e c) determinam $\left(\begin{array}{l}r \\ 2\end{array}\right)\left(\begin{array}{l}c \\ 2\end{array}\right)$ tipos de razões de chance da forma:

$$
\theta=\frac{\pi_{i j} \pi_{r c}}{\pi_{r j} \pi_{i c}}, \quad i=1, \ldots, r-1 \quad \text { e } \quad j=1, \ldots, c-1 .
$$

A independência de duas variáveis, neste caso, é equivalente à condição de que todas as razões de chances sejam iguais a 1 . 


\section{Razão de chances para Variáveis Ordinais}

No caso de variáveis ordinais há diversas formas para obtenção de um conjunto mínimo de raz̃̃es de chances. Serão descritas a seguir 3 tipos de razẽes de chances utilizados na prática que são: local, local-global e global.

\section{Local}

Uma maneira de calcular a razão de chances é:

$$
\theta_{i j}=\frac{\pi_{i j} \pi_{i+1, j+1}}{\pi_{i, j+1} \pi_{i+1, j}}, \quad i=1, \ldots, r-1 \quad e \quad j=1, \ldots, c-1,
$$

formada por caselas em linhas adjacentes e colunas adjacentes (Figura 2). Estes valores descrevem as magnitudes relativas das associaçøes locais na tabela, e não fazem distinção entre as variáveis de linhas e colunas , isto é, entre variáveis resposta e explanatórias. Os modelos que utilizam este tipo de razão de chances são chamados Modelos Log-lineares.

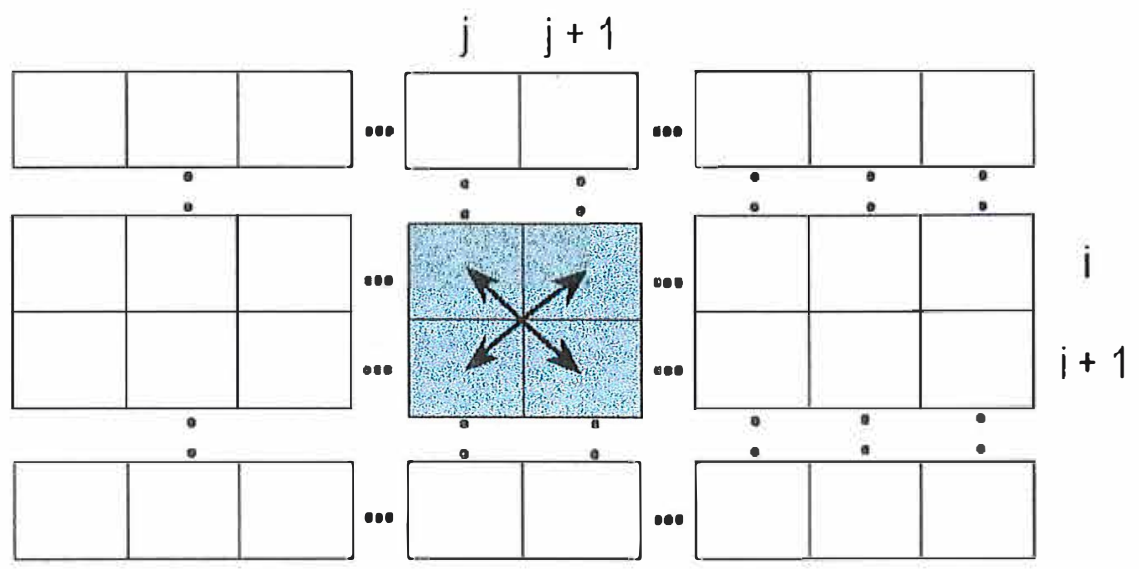

Figura 2: Razão de Chances Local. 


\section{Local-Global}

Outro tipo de construção de razões de chances é aquele "local" na variável da linha mas "global" na variável coluna (Figura 3), ou seja, todas as c categorias das colunas são usadas em cada razão de chances:

$$
\begin{aligned}
\theta_{i j}^{\prime}= & \frac{\left(\sum_{b \leq j} \pi_{i b}\right)\left(\sum_{b>j} \pi_{i+1, b}\right)}{\left(\sum_{b>j} \pi_{i b}\right)\left(\sum_{b \leq j} \pi_{i+1, b}\right)}=\frac{\gamma_{j(i)} /\left(1-\gamma_{j(i)}\right)}{\gamma_{j(i+1)} /\left(1-\gamma_{j(i+1)}\right)}, \\
& i=1, \ldots, r-1 \quad \text { e } \quad j=1, \ldots, c-1 .
\end{aligned}
$$

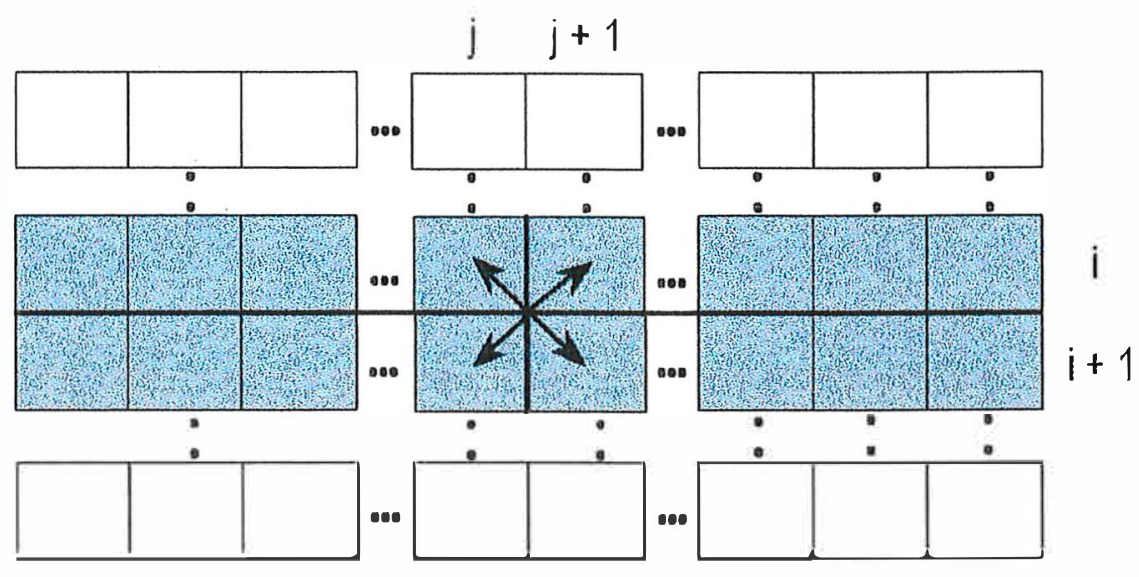

Figura 3: Razão de Chances Local-Global.

Para pares de linhas adjacentes $i$ e $i+1, \log \theta_{i j}^{\prime} \geq 0$ (ou $\theta_{i j}^{\prime} \geq 1$ ) para $j=$ $1, \ldots, c-1$ é equivalente a $\gamma_{j(i)} \geq \gamma_{j(i+1)}$. Deste modo, a distribuição na linha i+1 é estocasticamente maior do que a da linha i, ou seja, há maior concentração de probabilidade na linha $i+1$ para valores de mais alta ordem da variável coluna. A Figura 4 ilustra a ordenação estocástica para a função densidade correspondente ans $\pi_{j(i)}$ e a função distribuição contínua correspondente a $\gamma_{j(i)}$ (Agresti, 1984).

Este tipo de construção das razões de chances é utilizado nos Modelos Logit que fazem distinção entre a variável resposta e as explanatórias. 

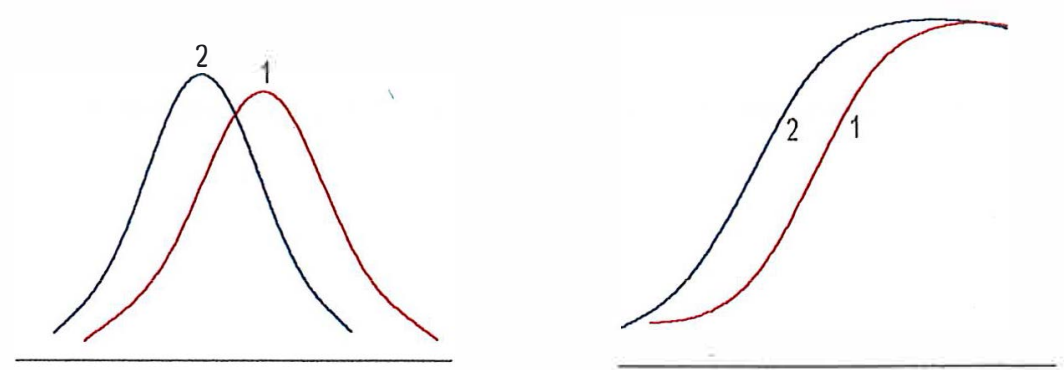

(a)
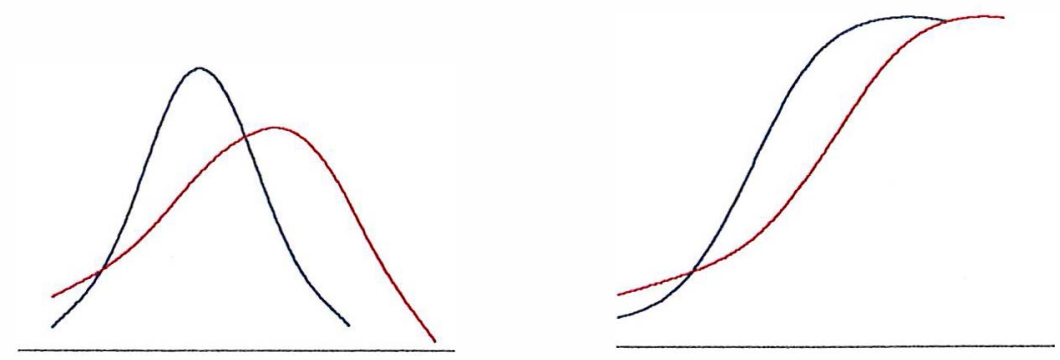

(b)

Figura 4: Distribuição 1 estocasticamente maior que a distribuição 2: (a) estocasticamente ordenada; (b) não estocasticamente ordenada.

\section{Global}

Uma terceira família de razões de chances para classificação cruzada de variáveis ordinais é aquela que descreve as associações de modo "global" em ambas as variáveis (Figura 5). Os modelos para este tipo são os Modelos Log-multiplicativos e os Modelos de Razão de Chances Global. A razão de chances global é dada por:

$$
\begin{aligned}
\theta_{i j}^{\prime \prime}= & \frac{\left(\sum_{a \leq i} \sum_{b \leq j} \pi_{a b}\right)\left(\sum_{a>i} \sum_{b>j} \pi_{a b}\right)}{\left(\sum_{a \leq i} \sum_{b>j} \pi_{a b}\right)\left(\sum_{a>i} \sum_{b \leq j} \pi_{a b}\right)} \\
= & \frac{\gamma_{i j}\left(1+\gamma_{i j}-\gamma_{i+}-\gamma_{+j}\right)}{\left(\gamma_{i+}-\gamma_{i j}\right)\left(\gamma_{+j}-\gamma_{i j}\right)}, \\
& i=1, \ldots, r-1 \quad e \quad j=1, \ldots, c-1 .
\end{aligned}
$$




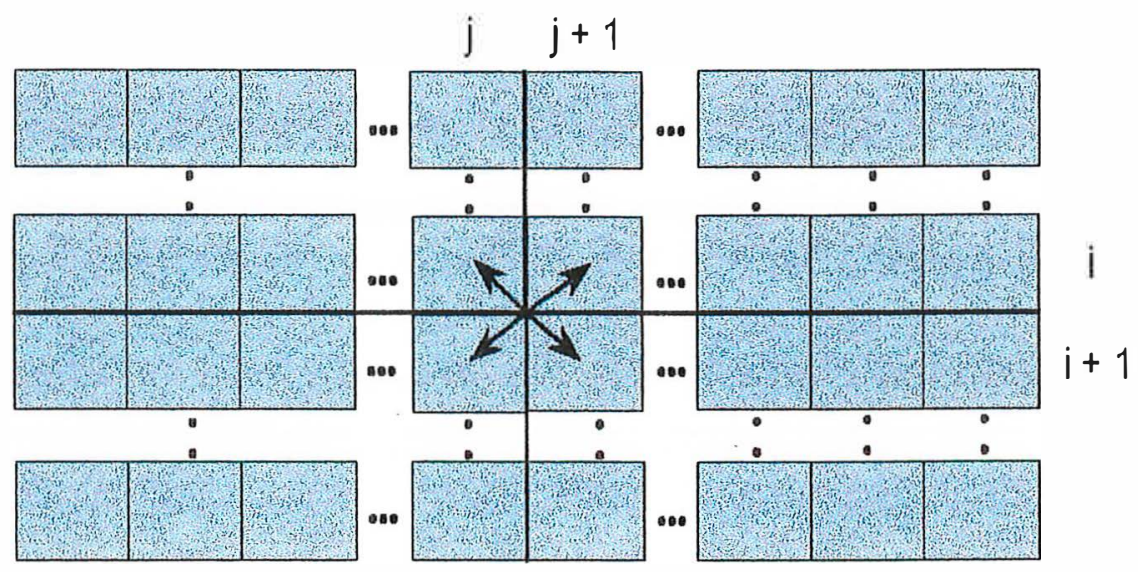

Figura 5: Razão de Chances Global.

\subsection{Modelos Lineares Generalizados}

Muitas técnicas foram desenvolvidas para a análise de tabelas de contingência, geralmente envolvendo a atribuição de escores às variáveis e usando procedimentos de análise como se fossem dados contínuos.

Nelder \& Wedderburn (1972) desenvolveram uma classe de modelos chamados Modelos Lineares Generalizados para lidar com modelos que envolvem distribuições pertencentes à Família Exponencial de Distribuições.

Os modelos lineares generalizados podem ser definidos (Demétrio, 1993) através de três componentes:

1. Um componente aleatório representado pelas variáveis aleatórias independentes $Y_{1}, Y_{2}, \ldots, Y_{n}$ provenientes da mesma distribuição que pertence à família exponencial na forma canônica;

$$
f\left(y_{i} ; \theta_{i}, \phi\right)=\exp \left\{\frac{1}{\phi}\left[y_{i} \theta_{i}-b\left(\theta_{i}\right)\right]+c\left(y_{i} ; \phi\right)\right\} ;
$$

onde $E\left(Y_{i}\right)=\mu_{i}=b^{\prime}\left(\theta_{i}\right)$ e $\operatorname{Var}\left(Y_{i}\right)=\phi b^{\prime \prime}\left(\theta_{i}\right)$.

2. Um componente sistemático linear nos parâmetros, chamado preditor linear

$$
\eta=X \beta,
$$


onde

$\eta=\left(\eta_{1}, \eta_{2}, \ldots, \eta_{n}\right)^{\prime}$ é o vetor de preditores lineares;

$\beta=\left(\beta_{1}, \beta_{2}, \ldots, \beta_{p}\right)^{\prime}, \quad 1 \leq p \leq n$, é o vetor de parâmetros;

$X=\left(X_{1}^{\prime}, X_{2}^{\prime}, \ldots, X_{n}^{\prime}\right)^{\prime}$ é a matriz de delineamento.

3. Uma função de ligação $g($.$) tal que$

$$
g\left(\mu_{i}\right)=x_{i}^{T} \beta
$$

onde $g$ é uma função monótona e diferenciável.

Nelder \& Wedderburn (1972) consideraram a solução das equações de máxima verossimilhança para os parâmetros dos modelos lineares generalizados e mostraram a equivalência ao procedimento de mínimos quadrados reponderados iterativamente para a estimação dos parâmetros. A Tabela 7 apresenta alguns casos de Modelos Lineares Generalizados.

Tabela 7: Tipos de modelos para análise estatística.

\begin{tabular}{llll}
\hline Comp. Aleat. & Ligação & Comp. Sist. & Modelo \\
\hline Normal & Identidade & Contínua & Regressão \\
Normal & Identidade & Categorizada & Análise de Variância \\
Normal & Identidade & Misto & Análise de Covariância \\
Binomial & Logit & Misto & Regressão Logística \\
Poisson & Log & Misto & Log-linear \\
Multinomial & Logit Gener. & Misto & Resposta Multinomial \\
\hline
\end{tabular}

Fonte: Agresti, A. (1996)

A principal aplicação de modelos lineares generalizados com distribuição Poisson está na análise de dados de contagens dispostos em Tabelas de Contingência. 
Modelos probabilísticos para tabelas de contingência são construídos sob a suposição de uma distribuição Poisson, multinomial ou um conjunto de distribuições multinomiais. O componente sistemático do modelo de tabelas de contingência é multiplicativo, que é linearizado através da função de ligação logarítmica.

\subsection{Adequacidade dos Modelos}

\subsubsection{Introdução}

O interesse do pesquisador é ajustar um modelo que seja parcimonioso e significativo de maneira que descreva o conjunto de dados em estudo. A escolha deste modelo pode ser feita sequencialmente seguindo uma hierarquia de modelos de acordo com o número de parâmetros envolvidos.

\subsubsection{Estatísticas de Pearson e Razão de Verossimilhança}

A estatística $X^{2}$ de Pearson dada por:

$$
X^{2}=\sum_{i} \sum_{j} \frac{\left(n_{i j}-\hat{m}_{i j}\right)^{2}}{\hat{m}_{i j}}
$$

foi a primeira medida criada para medir o grau de associação entre variáveis, isto é, para testar a hipótese $H_{0}$ :independência.

Posteriormente, Nelder \& Wedderburn (1972) sugeriram, como medida de qualidade de ajuste, a estatística logaritmo da razão de verossimilhança e a denominaram "Deviance", dada por:

$$
G^{2}=2 \log \lambda=2 \log \left[\frac{L\left(b_{\max } ; n_{i j}\right)}{L\left(b ; n_{i j}\right)}\right],
$$

onde $b_{\max }$ e $b$ são as estimativas de MV, sob os modelos corrente (sob estudo) e saturado, respectivamente.

Para o caso de tabelas de contingência cujas frequências seguem a distribuição de Poisson, tem-se:

$$
G^{2}=2\left[l\left(b_{m a x} ; n_{i j}\right)-l\left(b ; n_{i j}\right)\right]
$$




$$
\begin{aligned}
& =2\left[\sum_{i, j} n_{i j} \log n_{i j}-\sum_{i, j} n_{i j} \log \hat{m}_{i j}\right] \\
& =2 \sum_{i} \sum_{j} n_{i j} \log \left(\frac{n_{i j}}{\hat{m}_{i j}}\right)
\end{aligned}
$$

que sob a suposição de independência tem distribuição assintótica $\chi^{2}$ com $(r-1)(c-1)$ graus de liberdade.

Se o modelo ajustado está correto e o tamanho total amostral é grande, tanto $X^{2}$ como $G^{2}$ tem distribuição assintótica $\chi^{2}$ com número de graus de liberdade dado por:

g.l.=número de caselas - número de parâmetros ajustados.

Utilizando-se $G^{2}$ como uma medida de discrepância do modelo, as diferenças sequenciais desta medida, de um modelo para outro na hierarquia, irá conduzir à escolha do modelo que se ajuste bem aos dados.

A "deviance" é sempre maior ou igual a zero e, à medida em que entram variáveis explanatórias (ou covariáveis) no componente sistemático, a "deviance" decresce até tornar-se zero para o modelo saturado (Cordeiro, 1986; Demétrio, 1993). Uma vantagem da "deviance" sobre a estatística de Pearson é a aditividade. A diferença de "deviances" de dois modelos aninhados segue assintoticamente uma distribuição qui-quadrado com $g l_{1}-g l_{2}$ graus de liberdade (Agresti, 1984).

As estatísticas $X^{2}$ e $G^{2}$ são assintoticamente equivalentes em amostras muito grandes sob a hipótese de independência. Fienberg (1994) considerou amostra "muito grande" quando os tamanhos amostrais são pelo menos dez vezes maior do que o número de caselas na tabela, ou seja, $\frac{N}{\text { no.caselas }}>10$.

As regras para se definir o tamanho adequado da amostra surge da preocupação em se garantir uma boa aproximação das estatísticas com a distribuição qui-quadrado. Fisher (1950) e Cochran (1952), dada as limitações computacionais da época, propuseram que $80 \%$ das caselas deveriam ter frequências esperadas superiores a 5. Posteriormente, verificou-se que para testes conduzidos a um nível de 
significância de $5 \%$, a frequência mínima esperada deveria ser aproximadamente 1 (Fienberg, 1994).

Estudos mais recentes comprovam que mesmo com frequências esperadas muito pequenas a aproximação qui-quadrado pode ser muito boa. Fienberg (1994) explorou vários aspectos dos efeitos de tamanhos amostrais pequenos sobre as estatísticas $X^{2}$ e $G^{2}$, como o estudo de Monte Carlo, testes de melhoria da razão de verossimilhança e as aproximações assintóticas para o caso de tabelas muito esparsas.

Um artifício utilizado por pesquisadores para superar esse problema é o de combinar categorias adjacentes da variável resposta para obter uma tabela com frequências maiores nas caselas. Esta junção de categorias levará a uma redução da informação disponível, alteração no valor das estimativas, mas McCullagh \& Nelder (1989) alertaram que o ponto mais importante é que o mesmo parâmetro está sendo medido e a forma da conclusão não será afetada.

As estatísticas de teste citadas detectam evidência da associação entre variáveis, porém, a análise de diagnóstico fornece informações adicionais sobre a natureza desta associação.

\subsubsection{Resíduos}

Vários tipos de resíduos têm sido propostos na literatura. Agresti (1984) propôs o uso dos resíduos ajustados:

$$
R_{p}=\frac{n_{i j}-\hat{m}_{i j}}{\sqrt{\hat{m}_{i j}}}
$$

enquanto que Ilaberman (1974) propôs:

$$
\frac{n_{i j}-\hat{m}_{i j}}{\sqrt{\hat{m}_{i j}\left(1-p_{i+}\right)\left(1-p_{+j}\right)}} .
$$

Valores absolutos superiores a 3 indicam uma falta de ajuste do modelo de independência nestas caselas, ou seja, indicam que há uma discrepância entre o valor observado e o estimado maior do que seria esperado sob a suposição de independência das variáveis. 


\subsection{Modelos para Dados Categorizados Ordinais}

Na construção dos modelos cuja variável resposta é ordinal, os dados observados são as contagens ou frequências das caselas de uma tabela de contingência. A parte sistemática do modelo pode consistir de variáveis explicativas do tipo nominal (ou qualitativas), ordinal ou ambas. Quando as variáveis explicativas são nominais, a análise assemelha-se a uma análise de variância (ANOVA) onde cada fator possui $(r-1)$ graus de liberdade. Se as variáveis no modelo são variáveis quantitativas, o modelo assemelha-se a uma análise de regressão onde tem-se um único parâmetro para descrever a tendência positiva ou negativa da associação para cada variável explicativa.

\subsubsection{Modelos Log-lineares}

Na seção 4.2.2 viu-se que numa tabela bidimensional e sob a suposição de independência, $m_{i j}=N \pi_{i+} \pi_{+j}$, para todo $i$ e $j$. Aplicando os conceitos de MLG, verifica-se que na escala logarítmica, independência é equivalente à relação aditiva:

$$
\log \left(m_{i j}\right)=\log N+\log \pi_{i+}+\log \pi_{+j}
$$

ou seja, o logaritmo da frequência esperada para a casela $(i, j)$ é uma função aditiva do efeito da i-ésima linha (variável X) e da j-ésima coluna (variável Y). Uma formulação alternativa do modelo é

$$
\log \left(m_{i j}\right)=\mu+\lambda_{i}^{X}+\lambda_{j}^{Y}
$$

Seja:

$$
\begin{aligned}
& \lambda_{i}^{X}=\mu_{i .}-\mu \\
& \lambda_{j}^{Y}=\mu_{. j}-\mu \\
& \lambda_{i j}^{X Y}=\mu_{i j}-\mu_{i .}-\mu_{. j}+\mu
\end{aligned}
$$

onde $\mu_{i j}=\log \left(m_{i j}\right), \mu_{i .}=\sum_{j} \frac{\mu_{i j}}{c}, \mu_{. j}=\sum_{i} \frac{\mu_{i j}}{r}$ e $\mu=\mu_{. .}=\sum_{i} \sum_{j} \frac{\mu_{i j}}{r c}$, então segue que:

$$
\log \left(m_{i j}\right)=\mu+\lambda_{i}^{X}+\lambda_{j}^{Y}+\lambda_{i j}^{X Y} .
$$


Este modelo é chamado Modelo Log-linear para uma tabela $2 \times 2$, porém, apresenta uma limitação pois trata todas as classificações como nominais, sendo invariantes as estimativas dos parâmetros e as estatísticas qui-quadrado quanto à ordenação das categorias, isto é, não levam em consideração a informação adicional de uma variável ordinal. Outra característica do modelo é que não faz distinção entre variável resposta e variáveis exploratórias.

Agresti (1990) mostrou uma adaptação dos modelos log-lineares de forma a explorar a ordenação e aponta como vantagens destes sobre os de escala nominal:

1. os parâmetros do modelo descrevem tipos de tendência e são mais fáceis de interpretar;

2. é possível obter modelos não saturados em situações nas quais os modelos nominais são saturados;

3. o teste melhora o poder de detectar associação e interação.

Esses modelos são apresentados a seguir.

\subsubsection{Modelo de Associação Uniforme (Linear $\times$ Linear)}

O que se pretende é obter um modelo no sistema de hierarquia que seja parcimonioso e que se ajuste bem aos dados. No modelo com interação

$$
\log \left(m_{i j}\right)=\mu+\lambda_{i}^{X}+\lambda_{j}^{Y}+\lambda_{i j}^{X Y}
$$

acrescentam-se $(r-1)(c-1)$ parânnetros $\lambda_{i j}^{X Y}$ independentes ao modelo de independência (6), o que o torna saturado. Uma maneira de adaptar o modelo aos dados ordinais é atribuir escores para estruturar a associação.

Supondo-se que as variáveis de linhas e colunas sejam ordinais, atribuem-se escores $u_{i}$ e $v_{j}$, geralmente inteiros, ou seja, $u_{i}=i$ e $v_{j}=j$ para linhas e colunas, respectivamente, onde $u_{1}<u_{2}<\ldots<u_{r}$ e $v_{1}<v_{2}<\ldots<v_{c} \mathrm{e}$ 
considera-se o modelo:

$$
\log \left(m_{i j}\right)=\mu+\lambda_{i}^{X}+\lambda_{j}^{Y}+\beta\left(u_{i}-\bar{u}\right)\left(v_{j}-\bar{v}\right)
$$

onde $\sum_{i} \lambda_{i}^{X}=\sum_{j} \lambda_{j}^{Y}=0$. Desta forma o termo de associação envolve um único parâmetro $\beta$, e o resíduo tem rc- $[1+(\mathrm{r}-1)+(\mathrm{c}-1)+1]=\mathrm{rc}-\mathrm{r}-\mathrm{c}$ graus de liberdade.

Pode-se expressar o modelo (7) como

$$
\log \left(m_{i j}\right)=\text { independência }+\beta\left(u_{i}-\bar{u}\right)\left(v_{j}-\bar{v}\right) .
$$

Isso equivale a isolar 1 grau de liberdade da interação $\lambda^{X Y}$. O parâmetro $\beta$ descreve a associação entre $\mathrm{X}$ e Y. O termo $\beta u_{i} v_{j}$ reflete um desvio do $\log \left(m_{i j}\right)$ através do modelo de independência. Se

$\beta=0$ indica modelo de independência;

$\beta>0$ indica que mais observações são esperadas para valores (X pequeno, $\mathrm{Y}$ pequeno) e (X grande, Y grande);

$\beta<0$ indica que o desvio do $\log \left(m_{i j}\right)$ é positivo para (X grande, Y pequeno) e para (X pequeno, Y grande).

Denominou-se Modelo de Associação Linear $\times$ Linear pois o desvio do $\log \left(m_{i j}\right)$ é uma função linear em Y para X fixo e vice-versa (através dos escores $\left\{v_{i j}\right\}$ com inclinação $\beta u_{i}$ ).

Para quaisquer pares de linhas $a<b$, se $\beta>0$ existem relativamente mais observações em Y na linha $b$ do que na linha $a$. Isto é, a distribuição condicional de Y na linha $b$ é assintoticamente maior do que a distribuição condicional de Y na linha $a$ e, caso contrário, se $\beta<0$.

Para quaisquer pares de linhas $a<b$ e colunas $c<d$

$$
\log \left(\frac{m_{a c} m_{b d}}{m_{a d} m_{b c}}\right)=\beta\left(u_{b}-u_{a}\right)\left(v_{d}-v_{c}\right) .
$$

Isto quer dizer que o logaritmo da razão de chances formada por um retângulo de caselas é diretamente proporcional ao produto das distâncias entre as 
linhas e a distância entre colunas. Assim $\beta$ pode ser interpretado como o logaritmo das razões de chances por unidade de distância $u_{b}-u_{a}=v_{d}-v_{c}=1$ sobre $\mathrm{X}$ e Y, isto é,

$$
\log \left(\theta_{i j}\right)=\beta
$$

Goodman (1979) definiu modelos em termos de $(r-1)(c-1)$ razões de chances locais

$$
\theta_{i j}=\frac{m_{i j} m_{i+1, j+1}}{m_{i, j+1} m n_{i+1, j}}
$$

e denominou Modelo de Associação Uniforme quando todos os parâmetros $\theta_{i j}$ são iguais. A utilização de escores inteiros e equidistantes facilita a interpretação de $\beta$ como valor comum das razões de chances locais.

A obtenção das estimativas dos parâmetros é feita através do método de máxima verossimilhança. O logaritmo da função de verossimilhança para uma amostra com uma distribuição Poisson é dado por

$$
L=\sum_{i} \sum_{j} n_{i j} \log \left(m_{i j}\right)-\sum_{i} \sum_{j} m_{i j}
$$

Para os modelos de associação linear $\times$ linear fica:

$$
\begin{aligned}
L= & N \mu+\sum_{i} n_{i+} \lambda_{i}^{X}+\sum_{j} n_{+j} \lambda_{j}^{Y}+\beta \sum_{i} \sum_{j} u_{i} v_{j} n_{i j}- \\
& -\sum_{i} \sum_{j} \exp \left[\mu+\lambda_{i}^{X}+\lambda_{j}^{Y}+\beta u_{i} v_{j}\right] .
\end{aligned}
$$

Derivando-se $L$ em relação aos parâmetros $\lambda_{i}^{X}, \lambda_{j}^{Y}$ e $\beta$, e igualando-se a zero, obtêm-se as equações de verossimilhança:

$$
\begin{gathered}
\hat{m}_{i+}=n_{i+} \quad i=1, \ldots, r \\
\hat{m}_{+j}=n_{+j} \quad j=1, \ldots, c \\
\sum_{i} \sum_{j} u_{i} v_{j} \hat{m}_{i j}=\sum_{i} \sum_{j} u_{i} v_{j} n_{i j} .
\end{gathered}
$$

Considerando-se $p_{i j}=\frac{n_{i j}}{N}$ e $\hat{\pi}_{i j}=\frac{\hat{m}_{i j}}{N}$ as estimativas de MV de $\pi_{i j}$ tem-se que a terceira equação do sistema fica: 


$$
\sum_{i} \sum_{j} u_{i} v_{j} \hat{\pi}_{i j}=\sum_{i} \sum_{j} u_{i} v_{j} p_{i j}
$$

o que implica que a correlação entre os escores de $\mathrm{X}$ e $\mathrm{Y}$ é a mesma em ambas as distribuições marginais, ajustadas e observadas.

As equações não têm solução direta mas as estimativas de MV podem ser obtidas usando-se o método iterativo de Newton-Raphson.

\subsubsection{Modelo de Efeito de Linhas e Colunas}

Em muitas aplicações apenas uma das variáveis é ordinal, a variável resposta. Os modelos log-lineares apresentados aqui tratam ạ variável Y como ordinal e as demais como nominais.

\section{Modelo de Efeitos de Linha}

Novamente, utiliza-se um conjunto de escores $v_{1} \leq v_{2} \leq \ldots \leq v_{j}$ para representar a ordenação das colunas. O modelo log-linear para efeitos de linha é:

$$
\log \left(m_{i j}\right)=\mu+\lambda_{i}^{X}+\lambda_{j}^{Y}+\tau_{i} v_{j},
$$

onde $\sum_{i} \lambda_{i}^{X}=\sum_{j} \lambda_{j}^{Y}=\sum_{i} \tau_{i}=0$, sendo que $\tau_{i}$ representa o efeito das linhas. Deste modo, o número de graus de liberdade residual deste modelo é dado por:

$$
g l=r c-[1+(r-1)+(c-1)+(r-1)]=(r-1)(c-2) .
$$

Os parâmetros $\tau_{i}$ também podem ser interpretados através da razão de chances. Para um par arbitrário de linhas $h$ e $i$ e colunas adjacentes $j$ e $j+1$, tem-se que

$$
\log \left(\frac{m_{h j} m_{i, j+1}}{m_{h, j+1} m_{i j}}\right)=\tau_{i}-\tau_{h}
$$

Esta é uma medida de diferença entre duas linhas em relação à distribuição condicional de $\mathrm{Y}$.

Dado que o modelo ajusta-se bem, independência implica que:

$$
\tau_{1}=\tau_{2}=\ldots=\tau_{r}=0
$$


que pode ser testada usando-se $G^{2}(I / R)=G^{2}(I)-G^{2}(R)$ que, sob Ho, tem assintoticamente distribuição $\chi^{2}$ com $r-1$ graus de liberdade (assintoticamente mais poderosa que $G^{2}(I)$ que ignora a ordenação das colunas).

Aqui, também, a estimação dos parâmetros é feita pelo método de MV e as equações de verossimilhança para o modelo de efeitos de linhas são dadas por:

$$
\begin{array}{rlrl}
\hat{m}_{i+} & =n_{i+} & i & =1, \ldots, r \\
\hat{m}_{+j} & =n_{+j} & j & =1, \ldots, c \\
\sum_{i} v_{j} \hat{n}_{i j} & =\sum_{i} v_{j} n_{i j} & i & =1, \ldots, r .
\end{array}
$$

Neste modelo as distribuições marginais das frequências ajustadas e esperadas também são as mesmas. Considerando-se $\hat{\pi}_{j(i)}=\frac{\hat{m}_{i j}}{\hat{m}_{i+}}$ e $p_{j(i)}=\frac{n_{i j}}{n_{i+}}$, então a terceira equação de verossimilhança pode ser escrita como:

$$
\sum_{j} v_{j} \hat{\pi}_{j(i)}=\sum_{j} v_{j} p_{j(i)}
$$

As equações de verossimilhança podem ser resolvidas iterativamente, usando o algoritmo de Newton-Raphson.

\section{Modelo Log-linear para tabelas com maiores dimensões}

No caso de tabelas multidimensionais com variáveis ordinais, pode-se utilizar uma generalização dos modelos log-lineares apresentados. No caso tridimensional ocorrem:

- modelos de associação parcial que são mais parcimoniosos e mais simples de interpretar que o modelo de escala nominal $(\mathrm{XY}, \mathrm{XZ}, \mathrm{YZ}) \mathrm{e}$

- modelos que permitem interação tripla (parte linear) que, ao contrário do modelo (XYZ), não sejam saturados.

A Tabela 8 apresenta modelos log-lineares em tabelas de contingência tridimensional com a presença de variáveis explicativas de natureza ordinal ou nominal, enquanto que, a Tabela 9 mostra os respectivos graus de liberdade destes modelos. 
Tabela 8: Termos de associação para modelos log-lineares em tabelas de contingência tridimensional com efeitos ordinais lineares.

\begin{tabular}{llll}
\hline \multicolumn{4}{c}{ Termos de Associação } \\
\hline V. Ordinal & \multicolumn{1}{c}{$\mathrm{X}-\mathrm{Y}$} & \multicolumn{1}{c}{$\mathrm{X}-\mathrm{Z}$} & $\mathrm{Y}-\mathrm{Z}$ \\
\hline $\mathrm{X}, \mathrm{Y}, \mathrm{Z}$ & $\beta^{X Y}\left(u_{i}-\bar{u}\right)\left(v_{j}-\bar{v}\right)$ & $\beta^{X Z}\left(u_{i}-\bar{u}\right)\left(w_{k}-\bar{w}\right)$ & $\beta^{Y Z}\left(v_{j}-\bar{v}\right)\left(w_{k}-\bar{w}\right)$ \\
$\mathrm{Y}, \mathrm{Z}$ & $\tau_{i}^{X Y}\left(v_{j}-\bar{v}\right)$ & $\tau_{i}^{X Z}\left(w_{k}-\bar{w}\right)$ & $\beta^{X Y}\left(v_{j}-\bar{v}\right)\left(w_{k}-\bar{w}\right)$ \\
$\mathrm{Z}$ & $\lambda_{i j}^{X Y}$ & $\tau_{i}^{X Z}\left(w_{k}-\bar{w}\right)$ & $\tau_{j}^{Y Z}\left(w_{k}-\bar{w}\right)$ \\
\hline
\end{tabular}

Tabela 9: Graus de liberdade para modelos log-lineares em tabelas de contingência tridimensional com efeitos ordinais lineares.

\begin{tabular}{lc}
\hline V. Ordinal & g.l \\
\hline $\mathrm{X}, \mathrm{Y}, \mathrm{Z}$ & $r c l-r-c-l-1$ \\
$\mathrm{Y}, \mathrm{Z}$ & $r c l-3 r-c-l+3$ \\
$\mathrm{Z}$ & $r c l-r c-r-c-l+3$ \\
\hline
\end{tabular}

\subsubsection{Modelos "Logit"}

Os modelos "logit", em contraste com os log-lineares, descrevem efeitos de um conjunto de variáveis explicativas sobre a variável resposta. São mais simples de serem formulados por não descreverem associação e interação entre as variáveis explicativas, assim como os modelos de regressão para variáveis respostas quantitativas.

Existem várias maneiras de construir "logits", porém quando a variável resposta é ordinal deve-se formá-los de modo que a ordem das categorias seja considerada. Entre os tipos de "logit" citam-se:

\section{"Logit" Adjacente}

Os "logits" adjacentes são formados através da razão das frequências de uma categoria de resposta em relação à categoria adjacente, a diferença entre dois 
"logits" assim formados constitui o logaritmo da razão de chances local. Este "logit" é definido por:

$$
L_{j}=\log \left[\frac{\pi_{j+1}}{\pi_{j}}\right], \quad j=1, \ldots, c-1,
$$

que é equivalente ao "logit" de base ( "baseline") dado por:

$$
L_{j}=\log \left[\frac{\pi_{j}}{\pi_{c}}\right], \quad j=1, \ldots, c-1 .
$$

É usado quando o interesse está em comparar cada categoria da variável resposta a uma categoria base, que pode ser considerada em certos casos como o controle.

\section{"Logit" Cumulativo}

A construção deste "logit" baseia-se em formar razões entre as frequências acumuladas até a j-ésima categoria de resposta e as frequências das demais categorias. É definido da seguinte forma:

$$
L_{j(i)}=\log \left[\frac{\pi_{j+1}+\ldots+\pi_{c}}{\pi_{1}+\ldots+\pi_{j}}\right], \quad j-1, \ldots, c-1 .
$$

Podem-se formar $r(c-1)$ "logits" cumulativos. A diferença entre dois "logits" cumulativos constitui o logaritmo da razão de chances local-global (5). Este tipo de "logit" tem sido utilizado por vários autores e McCullagh (1980) denominou o modelo que usa o "logit" cumulativo como função de ligação, de Modelo de Chances Proporcionais ( "Proportional Odds Model"). Quando o modelo logístico linear é aplicado em dados binários é equivalente ao modelo log-linear. Este "logit" usa todas as $c$ categorias para cada "logit" e corresponde ao negativo dos valores da função de distribuição:

$$
L_{j}=-\log \left[\frac{\gamma_{j}}{1-\gamma_{j}}\right] \text {, }
$$

sendo $\gamma_{j}=\sum_{i \leq j} \pi_{i}$ e $L_{1} \geq L_{2} \geq \ldots \geq L_{r-1}$.

O modelo de chances proporcionais tem, então, como função de ligação: 


$$
\log i t\left(\gamma_{j}\right)=\log \frac{\gamma_{j}}{1-\gamma_{j}}
$$

"Logit" "continuation-ratio"

É o logaritmo da probabilidade do evento $j+1$ ocorrer, dado que já ocorreram $j$ categorias. Pode ser definido como:

$$
L_{j}=\log \left[\frac{\pi_{j+1}}{\pi_{1}+\ldots+\pi_{j}}\right], \quad j-1, \ldots, c-1 .
$$

Este "logit" difere de acordo com a disposição das categorias da variável ordinal. Uma alternativa é:

$$
L_{j}^{\prime}=\log \left[\frac{\pi_{j}}{\pi_{j+1}+\ldots+\pi_{\mathrm{c}}}\right], \quad j-1, \ldots, c-1,
$$

que é interpretada como o logaritmo das razões de probabilidades de risco, isto é, Modelo de Riscos Proporcionais ("Proportional Hazard Model"). Ajusta-se melhor a dados em que a variável resposta tem distribuição assimétrica, sendo muito utilizado em análise de sobrevivência.

\subsubsection{Modelo de Chances Proporcionais}

Esse modelo baseia-se em probabilidades acumuladas $\gamma_{j}=P(Y \leq j)$ (Tabela 10) ao invés das probabilidades correspondentes a cada categoria $\pi_{i j}$, por possuírem melhores propriedades para a escala ordinal.

Tabela 10: Probabilidades acumuladas das categorias ordinais.

\begin{tabular}{lll}
\hline Categorias & Probabilidades & Prob. Acumuladas \\
\hline 1 & $\pi_{1}$ & $\gamma_{1}=\pi_{1}$ \\
2 & $\pi_{2}$ & $\gamma_{2}=\pi_{1} \mid \pi_{2}$ \\
$\vdots$ & $\vdots$ & $\vdots$ \\
$\mathrm{c}$ & $\pi_{c}$ & $\gamma_{c}-\pi_{1}+\ldots+\pi_{c}$ \\
\hline$j=1, \ldots, c$ & 1. &
\end{tabular}


O modelo de independência é dado por:

$$
L_{j(i)}=\alpha_{j}
$$

onde $\alpha_{j}$ é chamado ponto de corte, sendo $\alpha_{1}<\alpha_{2}<\ldots<\alpha_{c-1} \operatorname{com}(r-1)(c-1)$ graus de liberdade, ou seja,

$$
r(c-1)-(c-1)=\text { número de "logits" - número de parâmetros. }
$$

Para $c=2$, o logaritmo da razão tem a seguinte relação linear:

$$
\log \left[\frac{\pi_{2(i)}}{\pi_{1(i)}}\right]=\alpha+\beta x_{i}
$$

Quando a variável resposta possui muitas categorias de resposta e há muitas variáveis explicativas, o modelo de regressão logística é generalizado para:

$$
L_{j(i)}=\log \left[\frac{1-\gamma_{j(i)}}{\gamma_{j(i)}}\right]=\alpha_{j}+\beta_{1} x_{1}+\ldots+\beta_{k} x_{k}=\alpha_{j}+\beta^{T} x_{i} .
$$

Estes modelos assumem que o logaritmo da razão de chances cumulativa é proporcional à distância entre os valores das variáveis explicativas, com proporcionalidade constante a cada ponto de corte. Devido a esta propriedade atribui-se o nome Modelo de Chances Proporcionais.

A Figura 6 ilustra o comportamento das probabilidades $\pi_{j}$ variando com $x$ para o caso de uma variável com $\beta>0$. Observa-se que quanto maior o valor de $x$ maior a probabilidade nas categorias de mais alta ordem. Nas categorias intermediárias as probabilidades são quase constantes, isto ocorre pois os modelos "logits" deslocam a média a cada categoria de maior ordem, enquanto que as categorias extremas podem-se alterar significativamente.

\section{a) Modelo de Efeito de Linhas (Tipo ANOVA)}

Considerando variáveis explicativas do tipo nominal, um modelo que tem efeitos aditivos das variáveis sobre o "logit" é:

$$
L_{j(i)}=\alpha_{j}+\tau_{i}, \quad 1 \leq i \leq r \quad e \quad 1 \leq j \leq c-1
$$




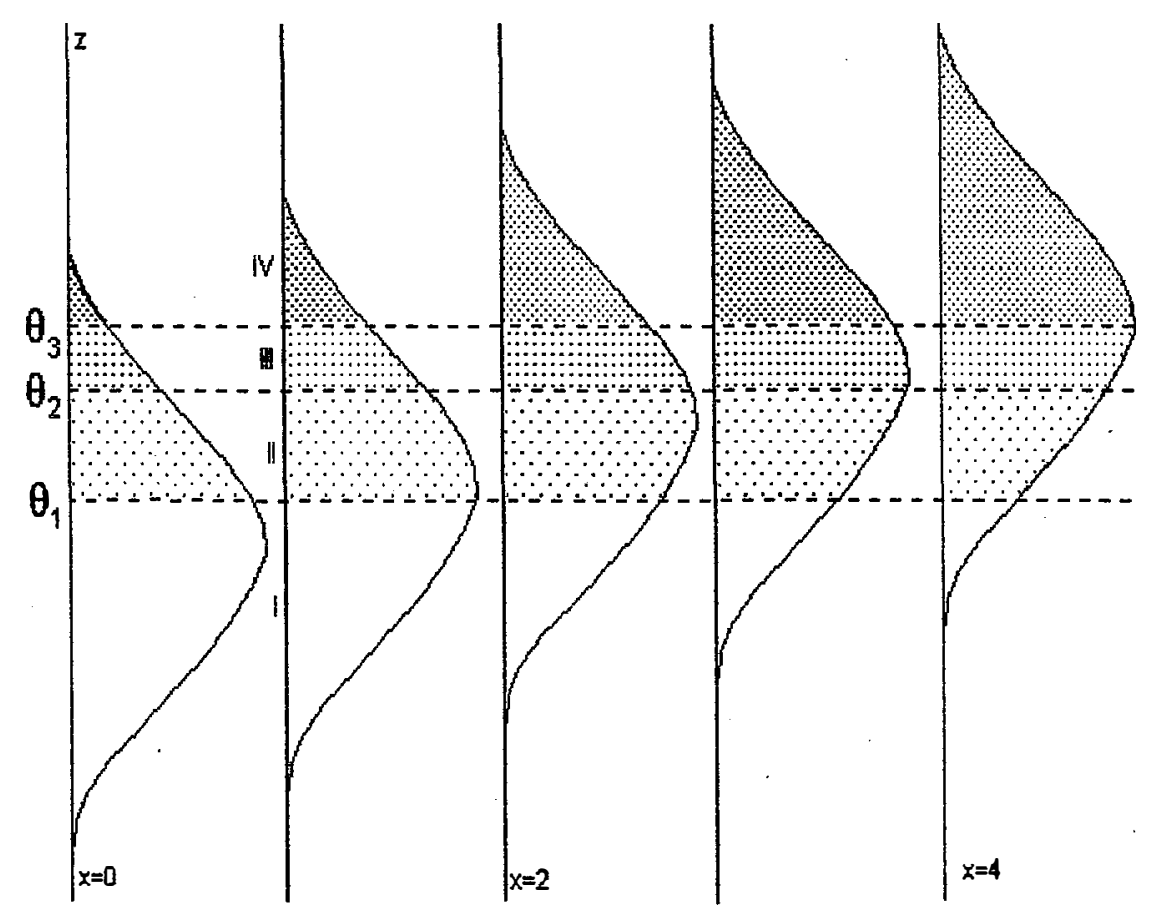

Figura 6: Probabilidades de resposta para o modelo de chances proporcionais variando com $x$ quando $\beta>0$.

satisfazendo à restrição $\sum_{i} \tau_{i}=0$ onde os $\tau_{i}$ descrevem a associação parcial entre as variáveis explicativas (ou efeito das linhas) sobre a variável resposta, ou seja, $\tau_{i}^{\prime} s$ fornecem a ordenação estocástica das linhas em relação à resposta ordinal.

No modelo existem $r(c-1)$ "logits" e $(c-1)+(r-1)$ parâmetros independentes, resultando em $(r-1)(c-2)$ graus de liberdade.

A diferença entre linhas corresponde ao logaritmo da razão de chances local-global, isto é:

$$
L_{j(i+1)}-L_{j(i)}=\tau_{i+1}-\tau_{i}=\log \left[\frac{\left(\pi_{1(i)}+\ldots+\pi_{j(i)}\right)\left(\pi_{j+1(i+1)}+\ldots+\pi_{c(i+1)}\right)}{\left(\pi_{j+1(i)}+\ldots+\pi_{r(i)}\right)\left(\pi_{1(i+1)}+\ldots+\pi_{j(i+1)}\right)}\right] .
$$

Se $\tau_{i+1}>\tau_{i}$, então a distribuição condicional de $Y$ é estocasticamente maior em $i+1$ do que em $i$.

A hipótese de independência é:

$$
H o: \tau_{1}=\ldots=\tau_{r}=0 .
$$


Dado que o Modelo de Efeito de Linhas está bem ajustado, o teste condicional de independência pode ser baseado em:

$$
G^{2}(I / R)=G^{2}(I)-G^{2}(R),
$$

que assintoticamente tem distribuição $\chi^{2} \operatorname{com}(r-1)(c-2)$.

\section{b) Modelo de Associação Uniforme (Tipo Regressão)}

No caso em que tanto a variável resposta como a explicativa são ordinais pode-se construir o Modelo de Chances Proporcionais

$$
L_{j(i)}=\alpha_{j}+\beta_{j}\left(u_{i}-\bar{u}\right), \quad i=1, \ldots, r
$$

onde $L_{j(i)}$ denota o j-ésimo "logit" cumulativo dentro da linha $i$, ou seja,

$$
L_{j(i)}=\log \left[\frac{\pi_{1(i)}+\ldots+\pi_{j(i)}}{\pi_{j+1(i)}+\ldots+\pi_{c(i)}}\right]=\log \left[\frac{m_{i 1}+\ldots+m_{i j}}{m_{i, j+1}+\ldots+m_{i c}}\right] .
$$

Sob a hipótese de que $\beta_{1}=\beta_{2}=\ldots=\beta_{c-1}$ o modelo é simplificado para a forma:

$$
L_{j(i)}=\alpha_{j}+\beta\left(u_{i}-\bar{u}\right), \quad 1 \leq i \leq r \quad e \quad 1 \leq j \leq c-1 .
$$

Este modelo para $(c-1)$ "logits" formados em cada uma das linhas, descreve $r(c-1)$ "logits". Aqui tem-se um único parâmetro de associação $\beta$ e $(c-1)$ parâmetros $\widehat{\alpha}_{j}$ pertencentes aos vários pontos de corte formados pelos "logits". O número de graus de liberdade para o resíduo é dado por:

$$
\text { g.l. }=r(c-1)=c-r c-r-c .
$$

Se o modelo está bem ajustado aos dados e $\beta=0$, então (para todo $j$ ), o j-ésimo "logit" é o mesmo em cada linha, o que implica que X e Y são independentes. Se $\beta>0$ o "logit" aumenta com o acréscimo em X, o que implica que a distribuição condicional de $\mathrm{Y}$ é estocasticamente maior para valores altos de $\mathrm{X}$.

$\mathrm{O}$ valor de $\beta$ também pode ser interpretado em termos do logaritmo das razões de chances: 
- $L_{j(i+1)}-L_{j(i)}$ para linhas adjacentes é o logaritmo da razão de chances localglobal $0_{i j}^{\prime}$ mostrada em (5). Para escores inteiros $u_{i}-i$, este "logit" é igual a $L_{j(i+1)}-L_{j(i)}=\beta, 1 \leq i \leq r-1$ e $1 \leq j \leq c-1$. Em outras palavras, $\exp (\beta)$ representa o valor constante das razões de chances $\theta_{i j}^{\prime}(5)$. Este modelo é denominado Modelo "Logit" de Associação Uniforme.

Para a estimação dos parâmetros, pelo método de máxima verossimilhança, McCullagh (1980) sugeriu o procedimento iterativo de Newton-Raphson. Após a estimação dos parâmetros do modelo (8), podem-se obter "logits" estimados e invertê-los para obter as frequências esperadas estimadas das caselas. A função de distribuição condicional

$$
\gamma_{j(i)}=\frac{\left(m_{i 1}+\ldots+m_{i j}\right)}{\left(m_{i 1}+\ldots+m_{i c}\right)}, \quad j=1, \ldots, c
$$

da variável resposta na linha $i$ está relacionada com o "logit" cumulativo $L_{j(i)}$ por

$$
L_{j(i)}=\log \left[\frac{\left(1-\gamma_{j(i)}\right)}{\gamma_{j(i)}}\right]
$$

de forma que

$$
\gamma_{j(i)}=\left[\exp \left(L_{j(i)}\right)+1\right]^{-1}
$$

O "logit" estimado $\hat{L}_{j(i)}$ fornece a probabilidade estimada $\hat{\gamma}_{j(i)}$ que multiplicada por $n_{i+}$ resulta na frequência esperada estimada $\hat{m}_{i j}$.

A hipótese de independência é: $H o: \beta=0$. A diferença entre o valor da razão de verossimilhança $G^{2}$ para o modelo de independência $(I)$ e o modelo "logit" de associação uniforme $(U)$ é:

$$
G^{2}(I / U)=G^{2}(I)-G^{2}(U)
$$

que assintoticamente tem distribuição $\chi^{2}$ com 1 grau de liberdade.

Para tabelas de mais alta ordem, podem-se resumir os termos de associação de acordo com a Tabela 11 e as inferências são feitas de forma semelhante à apresentada nos itens anteriores. 
Tabela 11: Termos de associação e graus de liberdade para modelos de chances proporcionais, com resposta ordinal $\mathrm{Z}$ e efeitos lineares de variáveis explicativas ordinais.

\begin{tabular}{rllll}
\hline Variáveis Explicativas & \multicolumn{4}{c}{ Termos de Associação } \\
\hline $\mathrm{X}$ & \multicolumn{1}{c}{$\mathrm{Y}$} & \multicolumn{1}{c}{$\mathrm{X}$} & \multicolumn{1}{c}{$\mathrm{Y}$} & $\mathrm{g} . l$ \\
\hline Ordinal & Ordinal & $\beta^{X}\left(u_{i}-\bar{u}\right)$ & $\beta^{Y}\left(v_{j}-\bar{v}\right)$ & $r c l-r c-l-1$ \\
Nominal & Ordinal & $\tau_{i}^{X}$ & $\beta^{Y}\left(v_{j}-\bar{v}\right)$ & $r c l-r c-l-c+l$ \\
Nominal & Nominal & $\tau_{i}^{X}$ & $\tau_{j}^{Y}$ & $r c l-r c-r-c-l+3$ \\
\hline
\end{tabular}

\subsubsection{Modelo de Riscos Proporcionais}

O Modelo de Riscos Proporcionais ("Proportional Hazards Model") é mais indicado quando a distribuição é exponencial ou assimétrica e utiliza o complemento log-log como função de ligação.

$$
\log \left(-\log \left(1-\gamma_{j}\right)\right)=\alpha_{j}-\beta^{T} x
$$

Este modelo é muito utilizado em análise de sobrevivência.

A Figura 7 ilustra o comportamento das probabilidades $\pi_{j}$ variando com $x$ para o caso de uma variável $\operatorname{com} \beta>0$.

Para dois níveis da variável independente $(i=1,2)$, pode-se interpretar o parâmetro $\beta$ da seguinte forma:

$$
\begin{gathered}
\log \left[-\log \left(1-\hat{\gamma}_{j(1)}\right)\right]-\log \left[-\log \left(1-\hat{\gamma}_{j(2)}\right)\right]=\beta \\
\log \left(1-\hat{\gamma}_{j(1)}\right)=e^{\beta} \log \left(1-\hat{\gamma}_{j(2)}\right)
\end{gathered}
$$

ou seja,

$$
\left(1-\hat{\gamma}_{j(1)}\right)=\left(1-\hat{\gamma}_{j(2)}\right)^{e^{\beta}} .
$$

Em outras palavras, a proporção de indivíduos nos valores mais altos da variável resposta no nível (1) da variável explicativa é igual ao do nível (2) elevada a uma potência igual a $e^{\beta}$. 


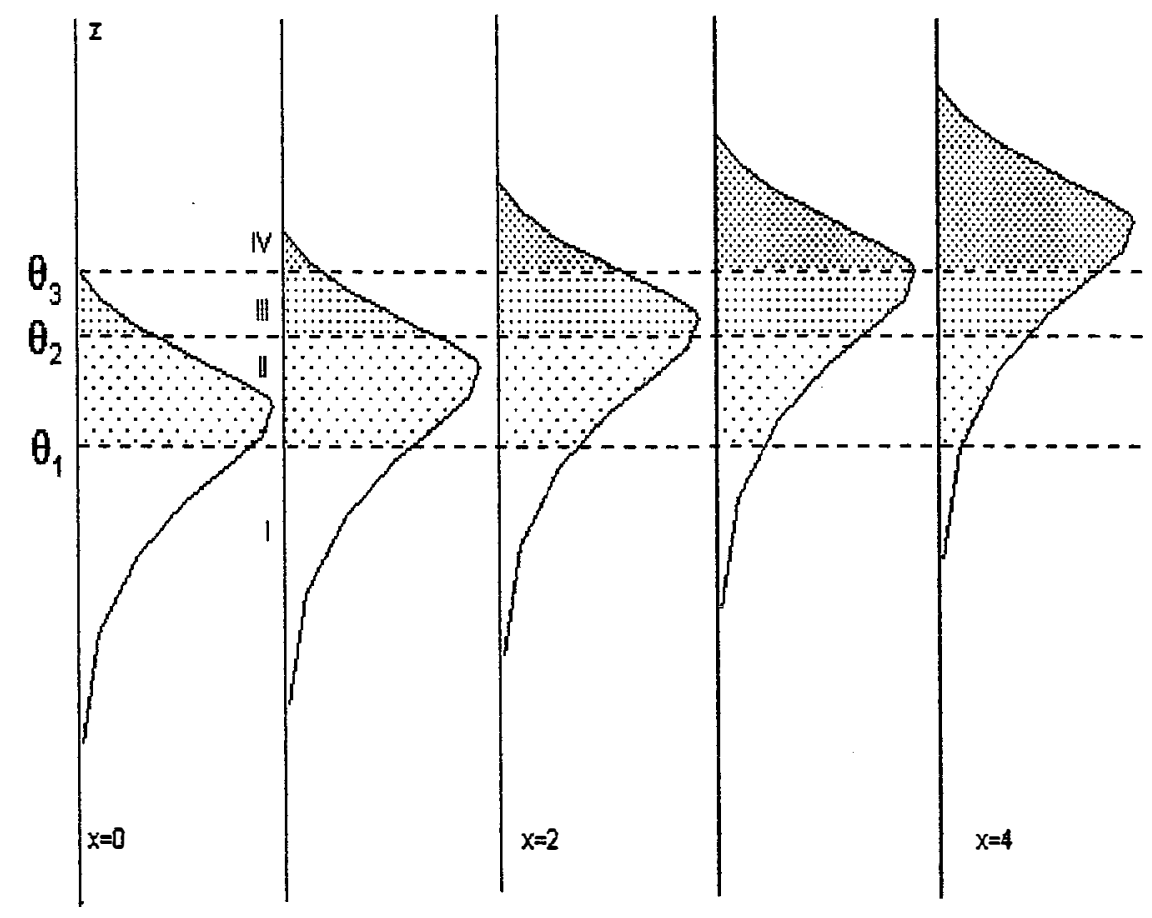

Figura 7: Probabilidades de resposta para o modelo complemento log-log variando com $x$ quando $\beta>0$.

\subsubsection{Modelos com Efeito de Escala}

O modelo de chances proporcionais considera constantes as razões de chances a cada ponto de corte. Quando as razões de chances crescem ou decrescem embora nem sempre de forma sistemática em $j$, surge a necessidade de se ajustarem modelos que incorporem um parâmetro de escala.

Supondo-se que uma variável latente $\mathrm{Z}$ tenha uma distribuição logística com média $\beta^{\prime} x$ e parâmetro de escala $\exp \left(\tau^{\prime} x\right)$, então,

$$
L_{i j}=\frac{Z-\beta^{\prime} x}{\exp \left(\tau^{\prime} x\right)},
$$

tem distribuição logística padronizada.

McCullagh \& Nelder (1989) consideraram os modelos não-lineares da seguinte forma: 


$$
\operatorname{logit}\left(\gamma_{j}(x)\right)=\frac{\alpha_{j}-\beta^{\prime} x}{\exp \left(\tau^{\prime} x\right)}
$$

onde $\beta^{\prime} x$ é o preditor linear para a média e $\tau^{\prime} x$ é o preditor linear para a dispersão ou variância. Segundo Wolfe (1996) outro modelo discutido por Kijewski et al. (op. cit:, p.6) é dado por:

$$
g\left(\gamma_{j}(x)\right)=\alpha_{j} \exp \left(\tau^{\prime} x\right)-\beta^{\prime} x
$$

Estes dois modelos já estão implementados na macro ORDINAL de Wolfe (1996), desenvolvida no GLIM4, além disso, o programa permite a utilização de outras funções de ligação além da "logit".

Se a diferença de "deviances" entre os modelos com e sem parâmetro de escala não é significativa, implica que não existe evidência de que a inclusão do parâmetro de escala no modelo seja necessária, portanto, escolhe-se o modelo mais simples.

\subsubsection{Outros tipos de modelos "Logit"}

A construção dos modelos "logit" depende da função de ligação escolhida e baseia-se na noção de uma distribuição de tolerância ou de uma variável aleatória subjacente não observada $\mathrm{Z}$, tal que $Z-\beta^{\prime} x$ tem distribuição logística.

$$
\begin{aligned}
P(Y \leq j) & =P\left(Z \leq \alpha_{j}\right)=P\left(Z-\beta^{T} x \leq \alpha_{j}-\beta^{T} x\right) \\
& =\frac{\exp \left(\alpha_{j}-\beta^{T} x\right)}{1+\exp \left(\alpha_{j}-\beta^{T} x\right)} .
\end{aligned}
$$

Além destas, outras funções monótonas crescentes são utilizadas como função de ligação. McCullagh (1980) citou a função normal inversa $\Phi^{-1}(j)$ ou probit apropriada quando a distribuição da resposta subjacente é normal, a função Cauchy inversa, $\arctan \pi(\gamma-0,05)$ e a função $\log (-\log (\gamma))$, embora a interpretação dos parâmetros não seja simples. A escolha apropriada da função de ligação deve depender primeiramente da facilidade de interpretação dos parâmetros. 
Nos modelos log-multiplicativos os escores para variáveis ordinais são tratados como parâmetros, o que é uma vantagem sobre os modelos que dependem da atribuição de escores. Este nome é devido ao fato de que o logaritmo das frequências esperadas é uma função multiplicativa (ao invés de linear) dos parâmetros do modelo.

\subsubsection{Exemplos de Aplicação}

\subsubsection{Aplicação em Fitopatologia}

No estudo da patologia do milho, o modelo que se ajustou bem aos dados foi o Modelo de Chances Proporcionais que utiliza o "logit" cumulativo como função de ligação e pode ser escrito da seguinte forma:

$$
\begin{aligned}
\log \left[\frac{\gamma_{j(i)}}{1-\gamma_{j(i)}}\right]= & \alpha_{j}+\tau_{i}^{L 1}+\tau_{k}^{L 2}+\tau_{i k}^{L 1 * L 2}, \\
& 1 \leq i \leq 3, \quad 1 \leq k \leq 3 \\
& e \quad 1 \leq j \leq 4
\end{aligned}
$$

onde:

$\alpha_{j}$ - é o j-ésimo ponto de corte;

$\tau_{i}^{L 1}$ - é o efeito do i-ésinno nível do locus bngl669 sobre a resistênncia à ferrugem comum;

$\tau_{k}^{L 2}$ - é o efeito do k-ésimo nível do locus bngl166 sobre a resistência à ferrugem comum;

$\tau_{i k}^{L 1 * L 2}$ - é o efeito da interação ou epistase entre o i-ésimo nível do locus bngl669 e o k-ésimo nível do locus bngl166 sobre a resistência à ferrugem comum.

A escala de notas varia de 1 a 9, porém, por falta de valores nas categorias extremas, optou-se em combinar as categorias de notas de 1 a 3 em uma única categoria, fazendo o mesmo para as notas de 7 a 9 . Assim, as categorias de notas ficaram definidas de acordo com: $3,4,5,6$ e 7 . 
A análise destes dados foi desenvolvida com o uso da macro ORDINAL no GLIM4 para o ajuste do modelo e estimativas dos parâmetros, porém, devido a alguns problemas na utilização da sub-macro INDI_DAT no GLIM4, tornou-se necessário o uso do PROC FREQ do SAS para a contrução da tabela de contingência e do PROC LOGISTIC que fornece os intervalos de confiança das razões de chances. Os programas encontram-se no Apêndice 1.

\subsubsection{Aplicação em Zootecnia}

Como neste exemplo o número de variáveis independentes é muito grande, aconselha-se a utilização de algumas estratégias para a seleção de variáveis para a construção do modelo logístico (IIosmer \& Lemeshow, 1989), isto é:

1. iniciar o processo com uma análise univariada de cada uma das variáveis explicativas com a resposta DIARRÉIA, eliminando aquelas que apresentaram (valor p) $>0,25$, critério sugerido por Bendel \& Afifi $^{8}$ citados por Hosmer \& Lemeshọw (1989);

2. proceder a uma análise de regressão múltipla, com as variáveis restantes e/ou consideradas de importância biológica, através dos métodos de seleção, tais como: "stepwise", "backward" ou "forward", ou ainda, "the best subset".

Inicialmente, na análise univariada, usando a metodologia para dados categorizados ordinais, estudou-se o ajuste de dois modelos: Modelo de Chances Proporcionais e o Modelo de Riscos Proporcionais. Desta forma, escolheu-se o modelo que melhor se ajustasse a cada grupo de variáveis, procedendo, em seguida, ao método de seleção para regressão múltipla, considerando um nível de significância de $5 \%$.

A análise destes dados foram feitas no SAS utilizando o PROC LOGISTIC por dispor da opção SELECT com possibilidade de escolha do método de

\footnotetext{
${ }^{8}$ BENDEL, R. B., AFIFI, A. A. Comparison of stopping rules in forward regression. Journal of the American Statistical Association, 72, p.46-53, 1977.
} 
seleção de variáveis na regressão múltipla e os programas desenvolvido nesta análise encontram-se no Apêndice 2. 


\section{RESULTADOS E DISCUSSÃO}

\subsection{Aplicação em Fitopatologia}

\section{a) Análise Descritiva .}

A Tabela 12 apresenta as frequências observadas em cada casela formada pela classificação cruzada entre os genótipos dos marcadores moleculares e o grau de severidade da doença, porém, praticamente nada se pode concluir da simples visualização desta tabela, somente merece salientar que possíveis problemas de convergência podem ocorrer dado que se trata de tabela esparsa.

Tabela 12: Frequências observadas.

\begin{tabular}{cc|rrrrr|r}
\hline \multicolumn{7}{c|}{ Marcador molecular } & \multicolumn{5}{|c|}{ Notas } & \\
$Q T L_{669}^{*}$ & $Q T L_{166}^{*}$ & 3 & 4 & 5 & 6 & 7 & Total \\
\hline 11 & 11 & 0 & 2 & 4 & 7 & 2 & 15 \\
22 & 11 & 0 & 1 & 3 & 4 & 4 & 12 \\
12 & 11 & 0 & 6 & 10 & 7 & 4 & 27 \\
\hline 11 & 22 & 5 & 1 & 0 & 0 & 0 & 6 \\
22 & 22 & 0 & 3 & 2 & 1 & 0 & 6 \\
12 & 22 & 6 & 8 & 8 & 4 & 1 & 27 \\
\hline 11 & 12 & 4 & 3 & 9 & 13 & 4 & 33 \\
22 & 12 & 4 & 2 & 12 & 10 & 5 & 33 \\
12 & 12 & 14 & 18 & 18 & 10 & 6 & 66 \\
\hline \multicolumn{2}{c|}{ Total } & 33 & 44 & 66 & 56 & 26 & 225 \\
\hline
\end{tabular}

* 1 e 2 denotam alelos $L_{10}$ e $L_{20}$, respectivamente. 
Uma forma de visualizar o comportamento da variável é calculando as probabilidades acumuladas até a j-ésima categoria de notas atribuídas ao grau de severidade da doença (Tabela 13).

Tabela 13: Probabilidades acumuladas observadas até a j-ésima categoria.

\begin{tabular}{cc|rrrrr}
\hline \multicolumn{3}{c|}{ Marcador molecular } & \multicolumn{5}{|c}{ Notas } \\
$Q T L_{669}^{*}$ & $Q T L_{166}^{*}$ & 3 & 4 & 5 & 6 & 7 \\
\hline 11 & 11 & 0,00 & 0,13 & 0,40 & 0,87 & 1,00 \\
22 & 11 & 0,00 & 0,08 & 0,33 & 0,66 & 1,00 \\
12 & 11 & 0,00 & 0,22 & 0,59 & 0,84 & 1,00 \\
\hline 11 & 22 & 0,83 & 1,00 & 1,00 & 1,00 & 1,00 \\
22 & 22 & 0,00 & 0,50 & 0,83 & 1,00 & 1,00 \\
12 & 22 & 0,22 & 0,52 & 0,82 & 0,97 & 1,00 \\
\hline 11 & 12 & 0,12 & 0,21 & 0,48 & 0,88 & 1,00 \\
22 & 12 & 0,12 & 0,18 & 0,54 & 0,84 & 1,00 \\
12 & 12 & 0,21 & 0,48 & 0,75 & 0,90 & 1,00 \\
\hline
\end{tabular}

* 1 e 2 denotam alelos $L_{10}$ e $L_{20}$, respectivamente.

A Figura 8, construída com base nas probabilidades acumuladas apresentadas na Tabela 13, mostra que a combinação do genótipo 11 no locus bngl669 e 22 no locus bngl1 66 proporciona maior resistência do milho à "ferrugem comum", visto que o genótipo 1122 apresenta frequências altas em valores mais baixos das notas atribuídas a esta doença. Analisando, primeiramente, o comportamento do marcador molecular bngl166, verifica-se que o genótipo 22 (linhas vermelhas) apresenta maior resistência do que o 12 (linhas verdes) que, por sua vez, parece ser ligeiramente superior ao genótipo 11 (linhas azuis). Analogamente, comparando-se os genótipos do bngl669, não se observa um padrão comum na ordenação dos símbolos utilizados para representá-lo (círculo, quadrado e triângulo para 11, 22 e 12, respectivamente), o que indicaria um efeito não tão evidente quanto ao primeiro. 


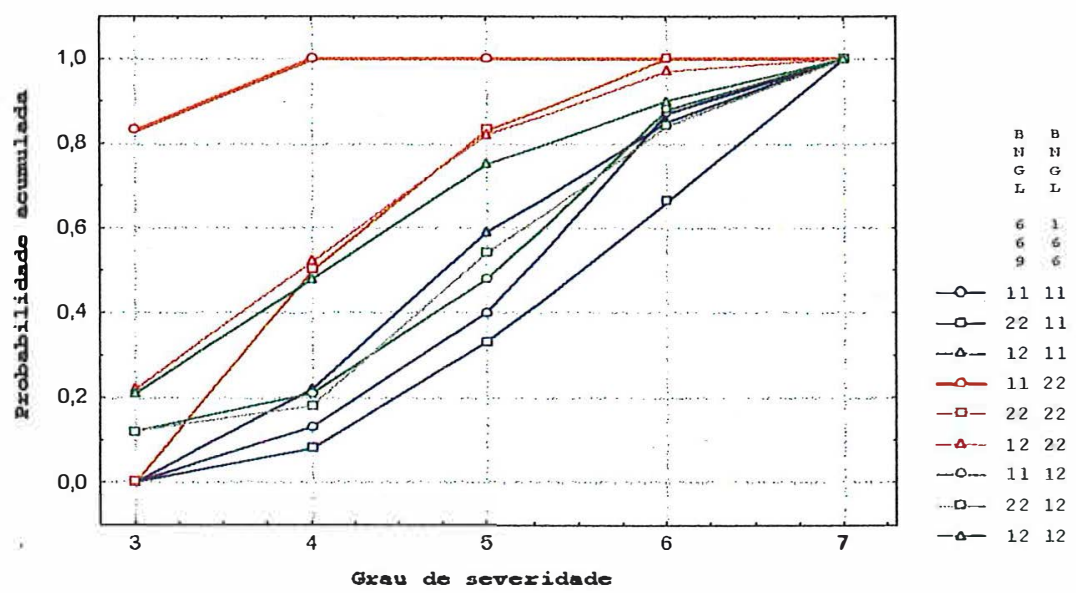

Figura 8: Probabilidade acumulada até a j-ésima categoria de nota atribuída à Ferrugem Comum provocada por Puccinia sorghi em milho.

\section{b) Ajuste do modelo}

A Tabela 14 apresenta os resultados da análise de deviance do delineamento experimental em blocos completos casualizados. A deviance residual foi de 67,09 com 94 g.l. mostrando que o Modelo de Chances Proporcionais, considerando o esquema fatorial com interação, ajusta-se bem aos dados (valor- $\mathrm{p}=0,984$ ). A suposição de paralelismo, ou seja, de que as chances têm proporcionalidade constante a cada ponto de corte, foi confirmado pelo teste escore com valor- $\mathrm{p}=0.697$.

Tabela 14: Análise de Deviance.

\begin{tabular}{lrrr}
\hline C. V. & G.L. & Deviance & Valor-p \\
\hline Pontos de & & & \\
Corte & 4 & & \\
Blocos & 2 & 13,70 & 0,001 \\
Bngl669 & 2 & 12,07 & 0,002 \\
Bngl166 & 2 & 24,28 & 0,000 \\
Bngl669/Bngl166 & 2 & 9,78 & 0,004 \\
Bngl166/Bngl669 & 2 & 21,99 & 0,000 \\
Bngl669*Bngl166 & 4 & 17,57 & 0,000 \\
Resíduo & 94 & 67,09 & 0,984 \\
\hline
\end{tabular}


A Figura 9 revela o comportamento dos resíduos padronizados para o modelo ajustado. É interessante notar que estes resíduos descrevem curvas paralelas, uma para cada frequência observada. À primeira vista, pode parecer problemático, porém Nelder (1990) alegou que este comportamento é uma característica dos modelos lineares generalizados, a menos que a $V(\mu)$ seja igual a 1 , isto torna diferente a forma de interpretar o gráfico de resíduos.

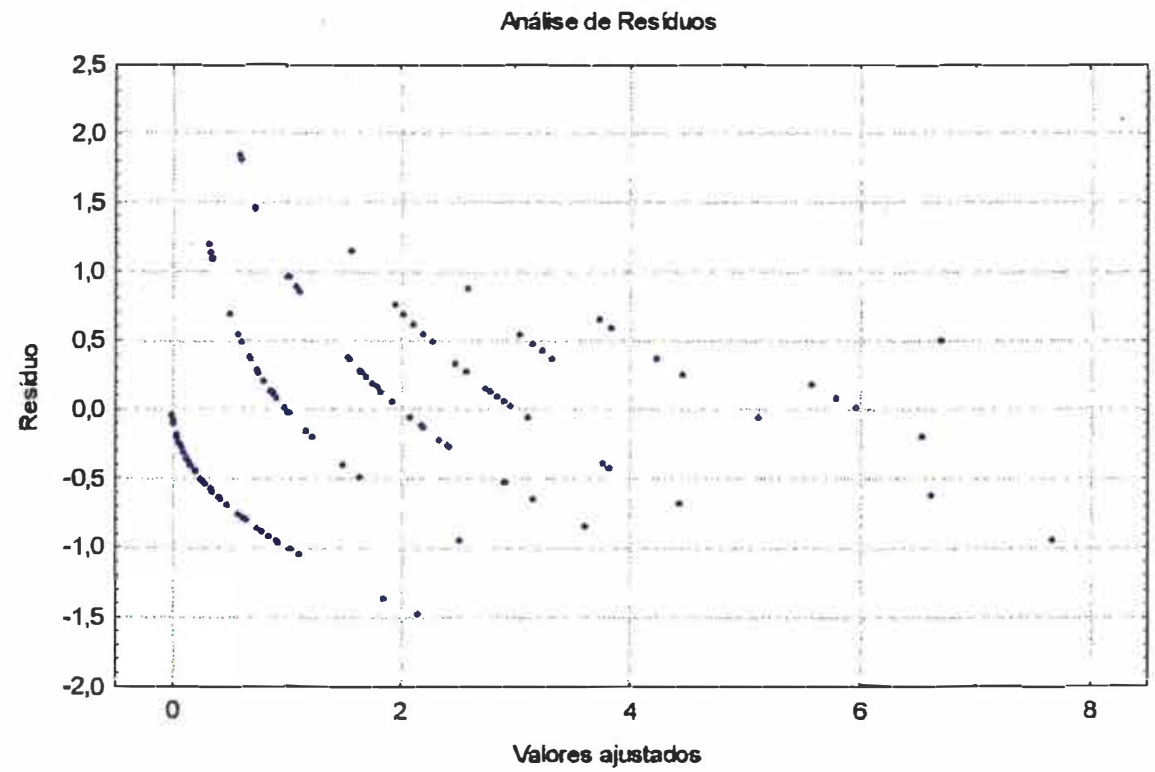

Figura 9: Dispersão dos Resíduos.

Dado que ainda não se dispõe de técnicas mais eficazes para a análise de resíduos nos modelos para dados categorizados ordinais, é razoável esperar que os resultados obtidos pelo ajuste do modelo confirmem os observados na análise descritiva.

Inicialmente, estudou-se a associação individual de cada um dos marcadores constatando-se tanto o efeito do bngl669 quanto do bngl166 no grau de severidade da doença, este último bastante evidenciado pelo valor da deviance, bem maior do que para o bngl669 (Tabela 14), confirmando os resultados da análise visual apresentada anteriormente. Em seguida, com a inclusão do termo bngl669*bngl166 (Tabela 14), observou-se a existência de interação entre os loci, o que significa que 
existe um comportamento diferenciado da ferrugem comum em milho para combinações diferentes de genótipos nos dois marcadores moleculares. Isto indica epistase,/ ou seja, os genes juntos atuam de forma diferenciada na manifestação da patologia. O interesse, portanto, é analisar que combinações de genótipos proporcionam plantas mais resistentes à doença e isto pode ser verificado através das estimativas dos parâmetros.

\section{c) Estimativa dos parâmetros}

A título de comparação, tomou-se por base o genótipo 12 para ambos os QTLs para o cálculo das razões de chances, por serem provenientes das duas populações segregantes L10 (resistente) e L20 (suscetível). É interessante destacar que qualquer outra combinação de genótipos poderia ser utilizada como base, dependendo da conveniência do pesquisador.

A Tabela 15 mostra as estimativas de máxima verossimilhança dos parâmetros, assim como as razões de chances calculadas com base nestes parâmetros. Verificam-se, desta forma, três grupos distintos de comportamento. O genótipo 11 para $Q T L_{669}$ e 22 para $Q T L_{166}$ foi aproximadamente 27 vezes mais resistente que o genótipo tomado por base, enquanto que os genótipos 22 e 12 para $Q T L_{669}$ combinados com 22 para $Q T L_{166}$ não apresentam diferenças significativas com relação ao genótipo tomado por base, como se pode constatar através da estatística de Wald ( $\mathrm{p}=0,8877$ e $\mathrm{p}=0,6193$, respectivamente). O terceiro grupo é formado pelos demais genótipos, onde se observa que o sinal do parâmetro inverte indicando que são mais suscetíveis à ferrugem comum. A estatística de Wald confirma a significância destes parâmetros ao nível de significância de $5 \%$. 
Tabela 15: Estimativas de Máxima Verossimilhança.

\begin{tabular}{lrrrrrr}
\hline Parâmetros & G.L. & Estimativas & D. P. & $\begin{array}{r}\text { Est. de } \\
\text { Wald }\end{array}$ & Valor-p & $\begin{array}{r}\text { Razão } \\
\text { Chances }\end{array}$ \\
\hline$\alpha_{1}$ & 1 & $-2,2405$ & 0,3357 & 44,5449 & 0,0001 &. \\
$\alpha_{2}$ & 1 & $-0,9045$ & 0,3011 & 9,0256 & 0,0027 &. \\
$\alpha_{33}$ & 1 & 0,5706 & 0,2991 & 3,6391 & 0,0564 &. \\
$\alpha_{4}$ & 1 & 2,2867 & 0,3422 & 44,6561 & 0,0001 &. \\
Bloco2 & 1 & 1,0411 & 0,3058 & 11,5926 & 0,0007 & 2,832 \\
Bloco3 & 1 & 1,1923 & 0,3079 & 14,9979 & 0,0001 & 3,295 \\
1111 & 1 & $-1,6034$ & 0,5297 & 9,1641 & 0,0025 & 0,201 \\
1122 & 1 & 3,3082 & 1,1837 & 7,8105 & 0,0052 & 27,337 \\
1112 & 1 & $-1,2492$ & 0,3953 & 9,9894 & 0,0016 & 0,287 \\
2211 & 1 & $-1,6516$ & 0,6541 & 6,3748 & 0,0116 & 0,192 \\
2222 & 1 & $-0,1083$ & 0,7675 & 0,0199 & 0,8877 & 0,897 \\
2212 & 1 & $-1,1945$ & 0,3945 & 9,1700 & 0,0025 & 0,303 \\
1211 & 1 & $-1,0245$ & 0,4046 & 6,4116 & 0,0113 & 0,359 \\
1222 & 1 & 0,2057 & 0,4140 & 0,2468 & 0,6193 & 1,228 \\
\hline
\end{tabular}

Os intervalos de confiança com um coeficiente de confiança de $95 \%$ de probabilidade para as estimativas das razões de chances foram calculados e encontram-se na Tabela 16. Verificou-se uma amplitude muito grande, entre 4,09 e 550,5, para o genótipo mais resistente, podendo indicar problemas de convergência devido à ocorrência de tabela esparsa. Pretende-se em estudos posteriores melhorar as estimativas destes parâmetros através de métodos exatos.

Tabela 16: Intervalos de confiança de $95 \%$ para as razões de chances.

\begin{tabular}{|c|c|c|c|c|}
\hline \multicolumn{2}{|c|}{ Marcador molecular } & Razão & Limite & $\overline{\text { Limite }}$ \\
\hline$Q T L_{669}$ & $Q T L_{166}$ & Chances & Inferior & Superior \\
\hline 11 & 11 & 0,204 & 0,075 & 0,542 \\
\hline 11 & 22 & 27,455 & 4,088 & 550,514 \\
\hline 11 & 12 & 0,290 & 0,132 & 0,631 \\
\hline 22 & 11 & 0,118 & 0,036 & 0,365 \\
\hline 22 & 22 & 0,906 & 0,231 & 3,505 \\
\hline 22 & 12 & 0,307 & 0,139 & 0,668 \\
\hline 12 & 11 & 0,327 & 0,143 & 0,737 \\
\hline 12 & 22 & 1,239 & 0,548 & 2,813 \\
\hline
\end{tabular}




\subsection{Aplicação em Zootecnia}

As Tabelas 17, 18 e 19 apresentam os valores das deviances para o ajuste dos modelos de chances proporcionais e o de riscos proporcionais, assim como, a diferença de deviances para a verificação da significância dos parâmetros nos modelos.

Tabela 17: Deviance residual para o ajuste dos modelos de chances proporcionais e riscos proporcionais e diferenças de deviances para a significância do parâmetro.

\begin{tabular}{|c|c|c|c|c|c|c|c|c|}
\hline & \multicolumn{4}{|c|}{ Chances Proporcionais } & \multicolumn{4}{|c|}{ Riscos Proporcionais } \\
\hline Variáveis & Modelo & G.L. & $\beta_{j}$ & G.L. & Modelo & G.L. & $\beta_{j}$ & G.L. \\
\hline VC. & $\begin{array}{r}0,7679 \\
(0,3809)\end{array}$ & 1 & $\begin{array}{r}11,481 \\
(0,0007)\end{array}$ & 1 & $\begin{array}{r}0,2015 \\
(0,6535)\end{array}$ & 1 & $\begin{array}{r}12,048 \\
(0,0005)\end{array}$ & $\mathbf{1}$ \\
\hline AP & $\begin{array}{r}1,0399 \\
(0,3078)\end{array}$ & 1 & $\begin{array}{r}0,5940 \\
(0,4408)\end{array}$ & 1 & $\begin{array}{r}1,5383 \\
(0,2149)\end{array}$ & 1 & $\begin{array}{r}0,096 \\
(0,7568)\end{array}$ & 1 \\
\hline VS & $\begin{array}{r}2,4313 \\
(0,2965)\end{array}$ & 2 & $\begin{array}{r}10,342 \\
(0,0057)\end{array}$ & 2 & $\begin{array}{r}6,8670 \\
(0,0323)\end{array}$ & 2 & $\begin{array}{r}5,9070 \\
(0,0522)\end{array}$ & 2 \\
\hline AG & $\begin{array}{r}9,2526 \\
(0,0024)\end{array}$ & 1 & $\begin{array}{r}7,324 \\
(0,0068)\end{array}$ & 1 & $\begin{array}{r}3,4550 \\
(0,0631)\end{array}$ & 1 & $\begin{array}{r}13,121 \\
(0,0003)\end{array}$ & 1 \\
\hline PSH & $\begin{array}{r}5,0721 \\
(0,1666)\end{array}$ & 3 & $\begin{array}{r}2,432 \\
(0,1189)\end{array}$ & 1 & $\begin{array}{r}6,3825 \\
(0,0944)\end{array}$ & 3 & $\begin{array}{r}1,121 \\
(0,2896)\end{array}$ & 1 \\
\hline $\mathrm{TP}$ & $\begin{array}{r}8,5853 \\
(0,0137)\end{array}$ & 2 & $\begin{array}{r}4,170 \\
(0,1243)\end{array}$ & 2 & $\begin{array}{r}11,8819 \\
(0,0026)\end{array}$ & 2 & $\begin{array}{r}0,873 \\
(0,6462)\end{array}$ & 2 \\
\hline PF & $\begin{array}{r}8,7528 \\
(0,0031)\end{array}$ & 1 & $\begin{array}{r}3,959 \\
(0,0466)\end{array}$ & 1 & $\begin{array}{r}12,2011 \\
(0,0005)\end{array}$ & 1 & $\begin{array}{r}0,510 \\
(0,4750)\end{array}$ & 1 \\
\hline PE & $\begin{array}{c}13,2324 \\
(0,0003)\end{array}$ & 1 & $\begin{array}{r}0,556 \\
(0,4559)\end{array}$ & 1 & $\begin{array}{r}13,2488 \\
(0,0003)\end{array}$ & 1 & $\begin{array}{r}0,5390 \\
(0,4626)\end{array}$ & 1 \\
\hline FSC & $\begin{array}{r}0,7056 \\
(0,4009)\end{array}$ & 1 & $\begin{array}{r}1,600 \\
(0,2059)\end{array}$ & 1 & $\begin{array}{r}0,0966 \\
(0,7560)\end{array}$ & 1 & $\begin{array}{r}2,209 \\
(0,1372)\end{array}$ & 1 \\
\hline PTE & $\begin{array}{r}14,0436 \\
(0,0002)\end{array}$ & 1 & $\begin{array}{r}1,289 \\
(0,2563)\end{array}$ & 1 & $\begin{array}{r}15,1612 \\
(0,0001)\end{array}$ & 1 & $\begin{array}{r}0,171 \\
(0,6792)\end{array}$ & 1 \\
\hline PAR & $\begin{array}{r}2,4944 \\
(0,1143)\end{array}$ & 1 & $\begin{array}{r}1,0180 \\
(0,3131)\end{array}$ & 1 & $\begin{array}{r}1,0568 \\
(0,3040)\end{array}$ & 1 & $\begin{array}{r}2,455 \\
(0,1171)\end{array}$ & 1 \\
\hline PNP & $\begin{array}{r}0,8185 \\
(0,3656)\end{array}$ & 1 & $\begin{array}{r}0,163 \\
(0,6865)\end{array}$ & 1 & $\begin{array}{r}0,9809 \\
(0,3220)\end{array}$ & 1 & $\begin{array}{r}0,001 \\
(0,9822)\end{array}$ & 1 \\
\hline TCO & $\begin{array}{r}0,4376 \\
(0,5083)\end{array}$ & 1 & $\begin{array}{r}3,668 \\
(0,0555)\end{array}$ & 1 & $\begin{array}{r}0,0139 \\
(0,9060)\end{array}$ & 1 & $\begin{array}{r}4,092 \\
(0,0431)\end{array}$ & 1 \\
\hline TRA & $\begin{array}{r}2,6353 \\
(0,1045) \\
\end{array}$ & 1 & $\begin{array}{r}0,014 \\
(0,9073) \\
\end{array}$ & 1 & $\begin{array}{r}2,094 \\
(0,1479) \\
\end{array}$ & 1 & $\begin{array}{r}0,555 \\
(0,4563)\end{array}$ & 1 \\
\hline
\end{tabular}


Tabela 18: Deviance residual para o ajuste dos modelos de chances proporcionais e riscos proporcionais e diferenças de deviances para a significância do parâmetro.

\begin{tabular}{|c|c|c|c|c|c|c|c|c|}
\hline & \multicolumn{4}{|c|}{ Chances Proporcionais } & \multicolumn{4}{|c|}{ Riscos Proporcionais } \\
\hline Variáveis & Modelo & G.L. & $\beta_{j}$ & G.L. & Modelo & G.L. & $\beta_{j}$ & G.L. \\
\hline NUT & $\begin{array}{r}0,9404 \\
(0,8157)\end{array}$ & 3 & $\begin{array}{r}0,988 \\
(0,3203)\end{array}$ & 1 & $\begin{array}{r}0,4890 \\
(0,9213)\end{array}$ & 3 & $\begin{array}{r}1,439 \\
(0,2303)\end{array}$ & 1 \\
\hline PD & $\begin{array}{r}4,4393 \\
(0,0351)\end{array}$ & 1 & $\begin{array}{r}0,047 \\
(0,8279)\end{array}$ & 1 & $\begin{array}{r}3,5052 \\
(0,0612)\end{array}$ & 1 & $\begin{array}{r}0,981 \\
(0,3219)\end{array}$ & 1 \\
\hline PAJ & $\begin{array}{r}8,9016 \\
(0,0306)\end{array}$ & 3 & $\begin{array}{r}4,085 \\
(0,0433)\end{array}$ & 1 & $\begin{array}{r}12,2379 \\
(0,0066)\end{array}$ & 3 & $\begin{array}{r}0,748 \\
(0,3870)\end{array}$ & 1 \\
\hline ARE & $\begin{array}{r}27,2977 \\
(0,0001)\end{array}$ & 3 & $\begin{array}{r}3,328 \\
(0,0681)\end{array}$ & 1 & $\begin{array}{r}30,1443 \\
(0,0001)\end{array}$ & 3 & $\begin{array}{r}0,482 \\
(0,4876)\end{array}$ & 1 \\
\hline ODP & $\begin{array}{r}6,6436 \\
(0,0842)\end{array}$ & 3 & $\begin{array}{r}0,769 \\
(0,3804)\end{array}$ & 1 & $\begin{array}{r}7,4072 \\
(0,0600)\end{array}$ & 3 & $\begin{array}{r}0,006 \\
(0,9395)\end{array}$ & 1 \\
\hline NLV & $\begin{array}{r}0,8332 \\
(0,8415)\end{array}$ & 3 & $\begin{array}{r}0,719 \\
(0,3964)\end{array}$ & 1 & $\begin{array}{r}1,2970 \\
(0,7298)\end{array}$ & 3 & $\begin{array}{r}0,255 \\
(0,6133)\end{array}$ & 1 \\
\hline NLD & $\begin{array}{r}1,9812 \\
(0,5763)\end{array}$ & 3 & $\begin{array}{r}0,796 \\
(0,3722)\end{array}$ & 1 & $\begin{array}{r}2,1578 \\
(0,5403)\end{array}$ & 3 & $\begin{array}{r}0,620 \\
(0,4311)\end{array}$ & 1 \\
\hline VAL & $\begin{array}{r}8,5010 \\
(0,0367)\end{array}$ & 3 & $\begin{array}{r}1,181 \\
(0,2771)\end{array}$ & 1 & $\begin{array}{r}5,3391 \\
(0,1490)\end{array}$ & 3 & $\begin{array}{r}4,349 \\
(0,0370)\end{array}$ & 1 \\
\hline NSP & $\begin{array}{r}3,2023 \\
(0,0735)\end{array}$ & 1 & $\begin{array}{r}5,305 \\
(0,0213)\end{array}$ & 1 & $\begin{array}{r}4,3722 \\
(0,0365)\end{array}$ & 1 & $\begin{array}{r}2,263 \\
(0,1325)\end{array}$ & 1 \\
\hline ASP & $\begin{array}{r}1,9783 \\
(0,1596)\end{array}$ & 1 & $\begin{array}{r}0,000 \\
(0,9938)\end{array}$ & 1 & $\begin{array}{r}1,6720 \\
(0,1960)\end{array}$ & 1 & $\begin{array}{r}0,306 \\
(0,5800)\end{array}$ & 1 \\
\hline NLP & $\begin{array}{r}13,3657 \\
(0,0039)\end{array}$ & 3 & $\begin{array}{r}0,708 \\
(0,4003)\end{array}$ & 1 & $\begin{array}{r}13,3115 \\
(0,0040)\end{array}$ & 3 & $\begin{array}{r}0,039 \\
(0,8434)\end{array}$ & 1 \\
\hline ADISP & $\begin{array}{r}1,1226 \\
(0,2894)\end{array}$ & 1 & $\begin{array}{r}0,106 \\
(0,7442)\end{array}$ & 1 & $\begin{array}{r}0,7165 \\
(0,3973)\end{array}$ & 1 & $\begin{array}{r}0,513 \\
(0,4740)\end{array}$ & 1 \\
\hline DAMPL16 & $\begin{array}{r}13,0737 \\
(0,0045)\end{array}$ & 3 & $\begin{array}{r}0,412 \\
(0,5207)\end{array}$ & 1 & $\begin{array}{r}13,4810 \\
(0,0037)\end{array}$ & 3 & $\begin{array}{r}0,005 \\
(0,9432)\end{array}$ & 1 \\
\hline DTMAX28 & $\begin{array}{r}0,0811 \\
(0,7758)\end{array}$ & 1 & $\begin{array}{r}1,231 \\
(0,2672)\end{array}$ & 1 & $\begin{array}{r}0,4859 \\
(0,4858)\end{array}$ & 1 & $\begin{array}{r}0,826 \\
(0,3633)\end{array}$ & 1 \\
\hline DTMIN16 & $\begin{array}{r}5,3705 \\
(0,0205)\end{array}$ & 1 & $\begin{array}{r}3,354 \\
(0,0670)\end{array}$ & 1 & $\begin{array}{r}8,1303 \\
(0,0044)\end{array}$ & 1 & $\begin{array}{r}0,594 \\
(0,4408)\end{array}$ & 1 \\
\hline CT 1824 & $\begin{array}{r}0,0779 \\
(0,7801)\end{array}$ & 1 & $\begin{array}{r}13,635 \\
(0,0002)\end{array}$ & 1) & $\begin{array}{r}2,8285 \\
(0,0926)\end{array}$ & 1 & $\begin{array}{r}10,885 \\
(0,0010)\end{array}$ & 1 \\
\hline MTMAX & $\begin{array}{r}0,0434 \\
(0,8350)\end{array}$ & 1 & $\begin{array}{r}0,564 \\
(0,4526)\end{array}$ & 1 & $\begin{array}{r}0,2362 \\
(0,6269)\end{array}$ & 1 & $\begin{array}{r}0,371 \\
(0,5423)\end{array}$ & 1 \\
\hline MTMIN & $\begin{array}{r}0,5915 \\
(0,4418)\end{array}$ & 1 & $\begin{array}{r}2,078 \\
(0,1495)\end{array}$ & 1 & $\begin{array}{r}1,6260 \\
(0,2023)\end{array}$ & 1 & $\begin{array}{r}1,043 \\
(0,3071)\end{array}$ & 1 \\
\hline MAMPLI & $\begin{array}{r}7,7519 \\
(0,0054)\end{array}$ & 1 & $\begin{array}{r}0,048 \\
(0,8257)\end{array}$ & 1 & $\begin{array}{r}6,2436 \\
(0,0125)\end{array}$ & 1 & $\begin{array}{r}1,557 \\
(0,2121)\end{array}$ & 1 \\
\hline PATOPAR & $\begin{array}{r}4,8561 \\
(0,1826) \\
\end{array}$ & 3 & $\begin{array}{r}3,530 \\
(0,0603)\end{array}$ & 1 & $\begin{array}{r}2,0107 \\
(0,5702)\end{array}$ & 3 & $\begin{array}{r}6,375 \\
(0,0116)\end{array}$ & 1 \\
\hline
\end{tabular}


Tabela 19: Deviance residual para o ajuste dos modelos de chances proporcionais e riscos proporcionais e diferenças de deviances para a significância do parâmetro.

\begin{tabular}{l|r|r|r|r|r|r|r|r}
\hline & \multicolumn{4}{|c|}{ Chances Proporcionais } & \multicolumn{4}{c}{ Riscos Proporcionais } \\
\hline Variáveis & Modelo & G.L. & $\beta_{\boldsymbol{j}}$ & G.L. & Modelo & G.L. & $\beta_{\boldsymbol{j}}$ & G.L. \\
\hline PMN & 195,3 & 195 & 0,265 & 1 & 195,6 & 195 & 0,000 & 1 \\
& $(0,4791)$ & & $(0,6070)$ & & $(0,4738)$ & & $(0,9859)$ & \\
PMD35 & 805,3 & 849 & 31,082 & 1 & 822,0 & 849 & 14,391 & 1 \\
& $(0,8563)$ & & $(\mathbf{0 , 0 0 0 1 )}$ & & $(0,7412)$ & & $(0,0001)$ & \\
GPM35 & 820,5 & 871 & 32,513 & 1 & 837,5 & 871 & 15,457 & 1 \\
& $(0,8885)$ & & $(\mathbf{0 , 0 0 0 1 )}$ & & $(0,7871)$ & & $(0,0001)$ & \\
CV35 & 847,7 & 879 & 8,088 & 1 & 846,8 & 879 & 8,965 & 1 \\
& $(0,7704)$ & & $(\mathbf{0 , 0 0 4 5 )}$ & & $0,7768)$ & & $(0,0028)$ & \\
STMORTE & 378,3 & 133 & 0,041 & 1 & 376,9 & 133 & 1,436 & 1 \\
& $(0,0001)$ & & $(0,8393)$ & & $(0,0001)$ & & $(0,2308)$ & \\
\hline
\end{tabular}

Constatou-se que algumas variáveis foram melhor ajustadas com o modelo de chances proporcionais e outras com o de riscos proporcionais.

Riscos Proporcionais:VC, AG, FSC, PAR, TCO, NUT, VAL, MAMPLI, PATOPAR;

Chances Proporcionais: VS, PF, ARE, NSP, DAMPLI16, DTMAX28, DTMIN16, CT1824.

A título de ilustração do modelo de riscos proporcionais, a análise foi desenvolvida apenas com as variáveis que melhor se ajustaram a este modelo. As variáveis que apresentaram significância a $25 \%$ para este modelo apresentam-se na Tabela 20 por ordem de importância na análise com uma variável. 
Tabela 20: Significância dos parâmetros, modelo de riscos proporcionais.

\begin{tabular}{lrcc} 
Variáveis & Deviances & g.l. & valor-p \\
\hline AG & 13,121 & 1 & 0,0003 \\
VC & 12,048 & 1 & 0,0005 \\
PATOPAR & 6,375 & 1 & 0,0116 \\
VAL & 4,349 & 1 & 0,0370 \\
TCO & 4,092 & 1 & 0,0431 \\
PAR & 2,455 & 1 & 0,1171 \\
FSC & 2,209 & 1 & 0,1372 \\
MAMPLI & 1,557 & 1 & 0,2121 \\
NUT & 1,439 & 1 & 0,2303 \\
\hline
\end{tabular}

Em seguida, estudou-se o comportamento em conjunto e, para isso, utilizou-se o método de seleção de variáveis para regressão múltipla "backward" para verificar quais os fatores de risco mais expressivos. A importância das interações também foi testada através das diferenças de deviances considerando-se o modelo com os termos principais e o outro acrescido da interação.

Tabela 21: Estudo das interações dos fatores de risco ajustados ao modelo de riscos proporcionais.

\begin{tabular}{lrc}
\hline Termos & Deviances & g.l. \\
\hline VC $\times$ TCO & 0,754 & 1 \\
AG $\times$ TCO & 3,867 & 1 \\
VC $\times$ PATOPAR & 3,235 & 1 \\
AG $\times$ PATOPAR & 0,284 & 1 \\
TCO $\times$ PATOPAR & 0,007 & 1 \\
\hline
\end{tabular}


Como pode ser observado na Tabela 21, não se justifica a inclusão de interações no modelo, optando-se, assim, por um modelo mais parcimonioso, ou seja, incluiu-se apenas os efeitos principais. A deviance residual de 28,221 com 42 g.l. (valor-p $=0,9489$ ) mostra que o modelo de riscos proporcionais ajustou-se bem aos dados e, no teste escore, verificou-se a suposição de paralelismo (valor-p=0.2883). A análise dos resíduos não apresentou valores superiores a 2 , o que confirma a qualidade do ajuste.

Os resultados das estimativas de Máxima Verossimilhança encontramse na Tabela 22 .

Tabela 22: Estimativas dos parâmetros do modelo de riscos proporcionais.

\begin{tabular}{lrrr}
\hline Parâmetros & Estimativas & D.P. & Potência \\
\hline$\alpha_{1}$ & $-0,5784$ & 0,1875 & \\
$\alpha_{2}$ & 0,6456 & 0,06111 & \\
VC & 0,4567 & 0,1427 & 1,59 \\
AG & 0,2471 & 0,1217 & 1,28 \\
TCO & 0,1611 & 0,1503 & 1,18 \\
PATOPAR & 0,2530 & 0,08843 & 1,29 \\
\hline
\end{tabular}

Através do modelo de riscos proporcionais, verificou-se que: a vacinação contra a colibacilose (VC), o tratamento com oxitocina (TCO) e o aleitamento em grupo (AG), quando adotados na granja, favorecem a presença de diarréia. Outro fator de risco que favorece à diarréia em leitões é a patologia de parto (PATOPAR) das porcas. 


\section{CONCLUSÕES}

1. A revisão feita sobre modelos adequados para a análise de dados categorizados ordinais permitiu ampliar o conhecimento na área e criar perspectivas para novos estudos, como por exemplo, a comparação com os modelos exatos, considerando-se categorias ordenadas.

2. Através do ajuste do modelo de chances proporcionais aos dados de avaliação de resistência de milho à ferrugem comum, causada por Puccinia sorghi, verificouse que:

- existe associação dos dois marcadores moleculares bngl669 e bngl166 localizados nos cromossomos 2 e 8 , respectivamente, com o grau de severidade da ferrugem comum em milho;

- existe efeito de epistase, ou seja, a ação conjunta destes marcadores moleculares sobre a doença foi verificado indicando a ação conjunta dos dois marcadores moleculares sobre a doença;

- a combinação genotípica mais resistente à Puccinia sorghi foi a formada por alelos provenientes da população resistente para o bngl669 e alelos provenientes da população suscetível para o bngl166 (1122); 
3. Através do ajuste do modelo de riscos proporcionais a um conjunto de dados de diarréia em leitões, conclui-se que os fatores de risco que favorecem a presença de diarréia são :

- a vacinação contra a colibacilose;

- o tratamento com oxitocina;

- o aleitamento em grupo, e

- a patologia de parto nas porcas. 


\section{REFERÊNCIAS BIBLIOGRÁFICAS}

AGRESTI, A. Analysis of ordinal categorical data. New York: John Wiley and Sons, 1984. 287p.

AGRESTI, A. Categorical data analysis. New York: John Wiley and Sons, 1990. $558 \mathrm{p}$

AGRESTI, A. An introduction to categorical data analysis. New York: John Wiley and Sons, 1996.

AITKIN, M.A.; ANDERSON, D.A.; FRANCIS, B., HINDE, J.P. Statistical modelling in GLIM. Oxford: Oxford University Press, 1989.

ANDERSON, J.A.; PHILIPS, P. R. Regression, discrimination and measurement models for ordered categorical variables. Applied Royal Statistics, 30, No. 1, p.22-31, 1981.

ANDERSON, J.A. Regression and ordered categorical variables. Journal of Royal Statistical Society Serie B, B46, No. 1, p.1-30, 1984.

ASHBY, D.; POCOCK, S.J.; SHAPER, A.G. Ordered polytomous regression: An example relating serum biochemistry and haematology to alcohol consumption. Applied Royal Statistics, 35, No. 3, p.289-301, 1986. 
BARIONI, W.J. Análise de correspondência na identificação dos fatores de risco associados à diarréia e à performance de leitões na fase de lactaão. Piracicaba, 1995. 97 p. Dissertação (M.S.) - Escola Superior de Agricultura "Luiz de Queiroz".

BARTLETT, M.S. Contingency table interactions. Journal of Royal Statistical Society, Suplement 2, p.248-252, 1935.

BISHOP, Y.V.V.; FIENBERG, S.E.; HOLLAND,P.W. Discrete Multivariate Analysis. Cambridge, MA: MIT Press, 1975.

CAMARGO, L.E.A., BOSCARIOL,, R.L., TOMBOLATO, DCM, PAINI, J.N., RESENDE, I.C. \& GUIMARÃES, M.A., A quantitative resistance locus of maize to Puccinia sorghi located on chromossome 2. INTERNATIONAL CONGRESS OF PLANT PATHOLOGY, 7., Edinburg, Scotland, 1998. p. 110.

COCHRAN, W.G. The $\chi^{2}$ test of goodness-of-fit. Ann. Math. Statist., No. 23, p.315-345, 1952.

CORDEIRO, G.M. Modelos Lineares Generalizados. Campinas: VII SINAPE, 1986. 286p.

COX, C. Location-scale cumulative odds models for ordinal data: A generalized non-linear model approach. Statistics in Medicine No. 14, p.1191-1203, 1995.

DEMÉTRIO, C.G.B. Modelos Lineares Generalizados na Experimentação Agronômica, 5 o SEAGRO e 38 $8^{\underline{a}}$ RRBRAS. Porto Alegre: DE/UFRGS, 1993.

DOBSON, A.J. An introduction to generalized linear models. London: Chapman-Hall, 1990. 174p. 
EKHOLM, A.; PALMGREN, J. Regression models for an ordinal response are best handled as nonlinear models. GLIM Newsletter, 18, p.31-35, 1988.

FIENBERG, S.E. The analysis of cross-classified categorical data. 2ed. The Massachusetts Institute of Tecnology, 1994.

FISHER, R.A. Contributions to Mathematical Statistics. New York: Wiley, 1950.

GART, J.J.; SWEIFUL, J.R. On the bias of various estimators of the logit and its variance with applications to quantal bioassay. Biometrika, No. 54, p.181-187, 1967.

GOODMAN, L.A. Simple models for the analysis of association in crossclassifications having ordered categories. Journal American Statist. Ass., 74, p.537-552, 1979.

GOODMAN, L.A. The analysis of dependence in cross-classifications having ordered categories, using log-linear models for frequencies and log-linear models for odds. Biometrics, 39, p.149-160, 1983.

GRIZZLE, J.E.; STARMER, C.F.; KOCH, G.G. Analysis of categorical data by linear models. Biometrics, 25, p.489-504, 1969.

HABERMAN, S.J. Log-linear models for frequency tables with ordered classifications. Biometrics, 30, p.589-600, 1974.

HEALY, M.J.R. GLIM : An introduction. Oxford: Oxford University Press, 1988. 130p.

HOLTBRÜGGE, W.; SCHUMACHER, M. A comparison of regression models for analysis of ordered categorical data. Applied Statist., 40, No. 2, p.249259, 1991. 
HOSMER, D. W.; LEMESHOW, S. A goodness-of-fit test for the multiple logistic regression model. Communs Statistics Theory Meth., 10, p.1043$1069,1980$.

HOSMER, D. W.; LEMESHOW, S. Applied Logistic Regression. New York: Wiley, 1989. 307p.

JANSEN, R. C. Complex plant traits: time for polygenic analysis. Trends in Plant Science Vol. 1, No. 3, 89-94, 1996.

LIPSITZ, S.R.; FITZMAURICE, G.M.; MOLENBERGHS, G. Goodnessof-fit tests for ordinal response regression models. Applied Statistics, 45, No. 2. p.175-190, 1996.

LIU, B.H Statistical Genomics: Linkage, Mapping and Qtl Analysis. USA: CRC Press LLC, 1998. 611p

MCCULLAGH, P. Regression models for ordinal data (with discussion). Journal of Royal Statistical Society Serie A, B42, p.109-142, 1980.

McCULLAGH, P.; NELDER, J.A. Generalized linear models. 2ed. London: Chapman-Hall, 1989.

NELDER, J.A.; WEDDERBURN, R.W.M. Generalised linear models. Journal of Royal Statistical Society Serie A, 135, p.370-84, 1972.

NELDER, J.A. Nearly parallel lines in residual plots. The American Statistician, 44, No. 3, p.221-222, 1990.

SAS Institute Inc., SAS/STAT ${ }^{T M}$ User's Guide, Release 6.03 Edition. Cary, NC: SAS Institute Inc., 1988. 1028p.

SAS Institute Inc., SAS Technical Report P-243, SAS/STAT Sofware: The GENMOD Procedure, Release 6.09, Cary, NC: SAS Institute Inc., 1993. 88p. 
TARAMINO, G.; TINGEY, S. A random set of maize simple sequence repeat markers. Maize Genetics Cooperation Newsletter 70, p.110-117, 1996.

TSIATIS, A.A. A note on the goodness of fit for the logistic regression model. Biometrika, 67, p.250-251, 1980.

WOLFE, R. General purpose macros to fit models to an ordinal response. GLIM Newsletter 26, p.20-27, 1996. 


\section{APÊNDICE 1}

\section{Aplicação em Fitopatologia}


a) GLIM - Macro Ordinal

\$units $135 \$$

\$gfactor blocos 3 locus2 3 (2) locus1 3 (2)\$

\$ass count $=0,0,0,3,2,0,0,0,2,2,0,2,3,2,2$,

$$
\begin{aligned}
& 1,1,0,0,0,0,0,1,1,0,1,3,2,2,1, \\
& 1,1,1,5,3,1,0,4,3,3,3,5,5,6,3, \\
& 0,0,3,2,0,0,0,2,2,0,0,2,3,3,1, \\
& 2,0,0,0,0,0,2,0,0,0,2,3,3,1,0, \\
& 1,0,5,4,1,1,2,3,4,1,5,8,6,2,1, \\
& 0,2,1,2,0,0,1,1,0,2,0,2,4,2,1, \\
& 2,0,0,0,0,0,1,1,0,0,3,2,3,1,0, \\
& 2,2,3,4,0,2,0,5,3,1,6,5,7,2,2 \$
\end{aligned}
$$

$\$$ ca cats $=\% g l(5,1)$ : rows $=\% g l(27,5) \$$

\$yvar count\$

\$input 'c: \glim4\ordinal.mac' ORDINAL\$

$\$ 1$ ist model=blocos, locus 1 , locus 2, i_2_3\$

\$use ORDINAL count rows cats\$

$\$ d r$ u $\$$

$\$ 1$ ist model $=$ blocos $\$$

\$use ORDINAL count rows cats\$

\$list model=blocos, locus $1 \$$

\$use ORDINAL count rows cats $\$$

$\$$ list model=blocos, locus $2 \$$

\$use ORDINAL count rows cats $\$$

$\$ 1$ ist model=blocos, locus 1 , locus $2 \$$

\$use ORDINAL count rows cats\$

\$list model=blocos, locus 1 , locus 2, i_2_3\$

\$use ORDINAL count rows cats $\$$

$\$$ tab the $\%$ fv $t$ for blocos, treat, cats $\$$

\$return\$

$\$$ ca cats $=\% g l(5,1)$ : rows $=\% g l(27,5) \$$

$\$ c$ trat $=\% g l(9,5) \$$

\$factor trat 9 (9)\$

\$yvar count\$ 
\$input 'c: \glim4 \ordinal.mac' ORDINAL\$

$\$$ list model=blocos, trat $\$$

\$use ORDINAL count rows cats $\$$

$\$ d$ u $\$$

$\$ 1$ ist model=blocos $\$$

\$use ORDINAL count rows cats $\$$

$\$$ list model=blocos, trat $\$$

$\$$ tab the $\%$ fv $t$ for treat, cats $\$$

\$return\$

b) Sistema SAS

data milho;

INFILE ' $\mathrm{K}$ : \milho\milho.PRN';

INPUT BLOCOS PROGENIE BNGL669 \$ BNGL166 \$ NOTA;

IF BNGL669=', OR BNGL166=', THEN DELETE;

$\mathrm{BL} 2=(\mathrm{BLOCOS}=2)$;

$\mathrm{BL3}=(\mathrm{BLOCOS}=3)$;

$\mathrm{A} 1=\left(\right.$ BNGL669 $\left.={ }^{\prime} \mathrm{A}^{\prime}\right)$;

$\mathrm{B} 1=\left(\right.$ BNGL669 $\left.=^{\prime} \mathrm{B}^{\prime}\right)$;

$\mathrm{H} 1=\left(\right.$ BNGL669 $\left.={ }^{\prime} \mathrm{H}^{\prime}\right)$;

$\mathrm{A} 2=\left(\mathrm{BNGL} 166={ }^{\prime} \mathrm{A}^{\prime}\right)$;

$\mathrm{B} 2=\left(\right.$ BNGL166 $\left.={ }^{\prime} \mathrm{B}^{\prime}\right)$;

$\mathrm{H} 2=\left(\right.$ BNGL166 $\left.={ }^{\prime} \mathrm{H}^{\prime}\right)$;

if 1 < nota <= 3 then GRAUSEV=3;

if $3<$ nota $<=4$ then GRAUSEV=4;

if $4<$ nota $<=5$ then GRAUSEV=5;

if 5 < nota <= 6 then GRAUSEV=6;

if $6<$ nota $<=9$ then GRAUSEV=7;

$\mathrm{A} 1 \mathrm{~A} 2=\mathrm{A} 1 * \mathrm{~A} 2$;

$\mathrm{A} 1 \mathrm{H} 2=\mathrm{A} 1 * \mathrm{H} 2$;

$\mathrm{H} 1 \mathrm{~A} 2=\mathrm{H} 1 * \mathrm{~A} 2$;

$\mathrm{H} 1 \mathrm{H} 2=\mathrm{H} 1 * \mathrm{H} 2$;

$\mathrm{A} 1 \mathrm{H} 2=\mathrm{A} 1 * \mathrm{H} 2$;

$\mathrm{H} 1 \mathrm{H} 2=\mathrm{H} 1 * \mathrm{H} 2$;

PROC PRINT; 
RUN;

PROC FREQ;

TABLES blocos*bngl166*bngl669*grausev; RUN;

PROC LOGISTIC DATA=MILHO;

MODEL GRAUSEV=BL2-BL3 A1 H1 A2 H2 A1A2 A1H2 H1A2 H1H2

/ aggregate=(BL2-BL3 A1 H1 A2 H2 A1A2 A1H2 H1A2 H1H2) scale=none clodds=both;

RUN; 
APÊNDICE 2

Aplicação em Zootecnia 
a) GLIM

\$slen 54\$

\$data OBS VC AG TCO PATOPAR CAT COUNT\$

\$read

$\begin{array}{rrrrrrr}1 & 0 & 0 & 0 & 1 & 1 & 15 \\ 2 & 0 & 0 & 0 & 1 & 2 & 19 \\ . & . & . & . & . & . & . \\ . & . & . & . & . & . & . \\ . & . & . & . & . & . & . \\ 72 & 1 & 1 & 1 & 3 & 3 & 0\end{array}$

\$yvar count\$

\$factor vc 2 ag 2 tco $2 \$$

\$ca rows $=\% g l(24,3) \$$

\$link c\$

\$list model=vc, ag, tco, patopar $\$$

\$input 'c:\glim4\ordinal.mac' ordinal\$

\$use ordinal count rows cat\$

$\$ \mathrm{~d}$ u $\$$

\$return\$

b) Sistema SAS

options nodate nonumber pagesize $=200$ linesize $=75$;

data leitoa;

infile 'c:\lena\leitoa\leitoa.dad';

input OBS CDG VC AP VS AG PSH TP PF PE FSC PTE PAR PNP TCO TRA NUT NUT1

PMD351 GPM35 GPM351 CV35 CV351 STMORTE STMORTE1 PDIAR35 PDIAR351

VAL VAL1 NSP NSP1 ASP ASP1 NLP NLP1 ADISP ADISP1 DAMPL16 DAMPL161

DTMAX28 DTMAX281 DTMIN16 DTMIN161 CONF1824 CT18241 MTMAX MTMAX1

MTMIN MTMIN1 MAMPLI MAMPLI1 PATOPAR PATOPAR1;

run;

proc print;

run cancel;

proc logistic; 


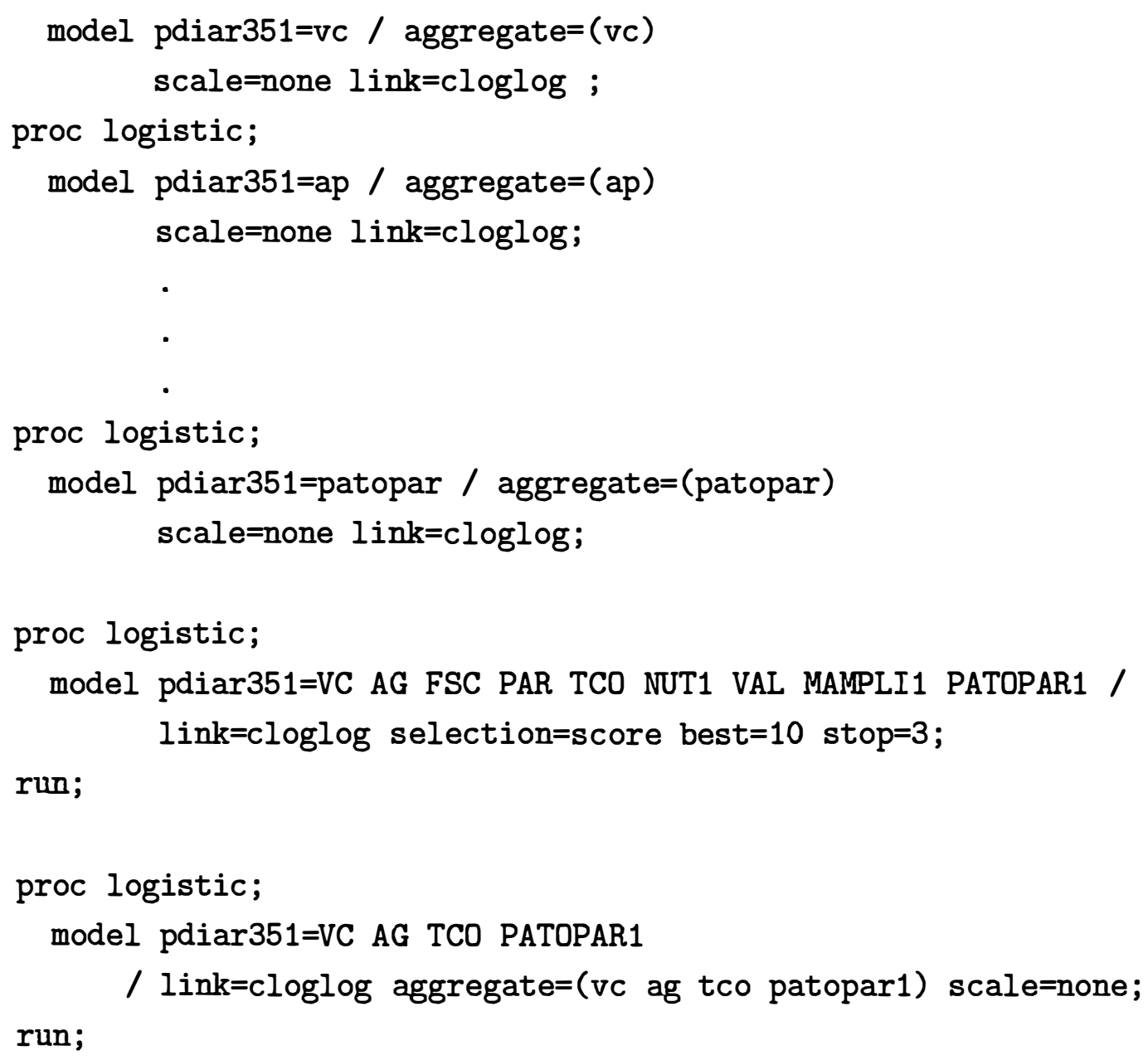

